\title{
Experimental and Analytical Assessment of Ductility \\ in Lightly Reinforced Concrete Members
}

\author{
K.A. Cashell, A.Y. Elghazouli* and B.A. Izzuddin \\ Department of Civil and Environmental Engineering, Imperial College London, UK
}

\begin{abstract}
This paper is concerned with the ultimate behaviour of lightly reinforced concrete members under extreme loading conditions. Although the consideration given to the assessment of ductility is of general relevance to various applications, it is of particular importance to conditions resembling those occurring during severe building fires. The main purpose of the investigation is to examine the failure of idealised members representing isolated strips within composite floor slabs which become lightly reinforced in a simulated fire situation due to the early loss of the steel deck. An experimental study, focusing on the failure state associated with rupture of the reinforcement in idealised concrete members, is presented. The tests enable direct assessment of the influence of a number of important parameters such as the reinforcement type, properties and ratio on the ultimate response. The results of several tests also facilitate a detailed examination of the distribution of bond stresses along the length. After describing the experimental arrangements and discussing the main test results, the paper introduces a simplified analytical model that can be used to represent the member response up to failure. The model is validated and calibrated through comparisons against the test results as well as more detailed nonlinear finite element simulations. The results and observations from this investigation offer an insight into the key factors that govern the ultimate behaviour. More importantly, the analytical model permits the development of simple expressions which capture the influence of salient parameters such as bond characteristics and reinforcement properties, for predicting the ductility of this type of member. With due consideration of the findings from other complementary experimental and analytical studies on full slab elements under ambient and elevated temperature, this work represents a proposed basis for developing quantified failure criteria.
\end{abstract}




\section{Introduction}

The performance of steel-framed buildings with composite steel-concrete floors under fire conditions has been the subject of considerable research effort in recent years. The mounting attention directed to this area has been driven partly by the desire to achieve more costeffective steel construction and, importantly, by the need to advance the understanding of structural fire response with a view to improving the rationale of design. A significant part of earlier activities in this area has been related to the fire tests conducted in the UK by the Building Research Establishment and Corus (formerly British Steel) on the full-scale eightstorey building at Cardington $[1,2]$. The findings of these tests, coupled with other numerical and experimental studies [e.g. 3-8], have identified the important role played by the composite floor slab in carrying the gravity loading within the fire compartment after the loss of strength in the supporting secondary steel beams due to elevated temperature. Moreover, due to the early development of high temperature in the thin steel deck located at the bottom of the composite slab, its contribution to the resistance becomes insignificant. As a result, the slab behaves similarly to a lightly reinforced concrete member with an effective reinforcement mesh that remains at comparatively low temperature.

Previous theoretical, numerical and experimental studies [e.g. 3-8] have permitted a greater insight into the large displacement behaviour of floor slab systems. Comparison with available fire tests has also illustrated that the main elevated temperature effects, namely reduction in material properties as well as thermal expansion and curvature, can be closely replicated in the analysis. However, there remains a need for a fundamental examination of appropriate failure criteria that can be implemented within design guidance. One of the key failure conditions is that related to the rupture of reinforcement in the slab. Although the adoption of a conventional smeared crack approach within numerical models provides good predictions of the load-deflection response of lightly reinforced members, it cannot reliably assess the strain concentrations across cracks. This is because such concentrations are unrealistically dependant on the element size rather than the geometric and material characteristics. Due to the complexity of the problem and the absence of more detailed investigations, typical design methods [e.g. 4, 5] account for the limiting criteria using 
simplified approaches. These methods generally ignore the influence of several important material and geometric properties, such as reinforcement ratio and bond characteristics.

Recent studies carried out at Imperial College have focused on developing analytical models for assessing failure [e.g. 9-11]. New procedures which predict the deformation and load levels corresponding to failure, at both ambient and elevated temperature, have been proposed. The approach was firstly developed for slab strips [9, 10] and more recently extended to represent slabs of various geometry and boundary conditions [11]. The models realistically capture the effects of key material and geometric parameters including bond characteristics, member length, steel material response and temperature effects. This paper describes the first phase of complementary laboratory studies; it forms part of a wider research programme which includes experimental and analytical assessments on isolated strips as well as full slab elements covering a wide range of material properties, geometric considerations and boundary conditions. In particular, this paper describes tests carried out on thirteen simply supported specimens representing isolated strip elements. For comparison purposes, the reinforcement ratio was varied between 0.24 and $0.52 \%$, and both plain and deformed bars, as well as mesh configurations, were considered. Three of the tests were instrumented with strain gauges embedded within the reinforcement in order to investigate the distribution of bond along the length.

After describing the experimental arrangements and discussing the main test results, the paper introduces a simplified analytical model that can be used to represent the member response up to failure. The model is validated and calibrated through comparisons against the test results as well as more detailed nonlinear finite element simulations. Importantly, the comparative assessments enable the calibration of realistic levels of idealised bond properties that can be used in analytical models for predicting the ultimate response. Although the work presented in this paper is restricted to one-dimensional strip elements, it accounts for the influence of key material and geometric parameters and represents a necessary step towards a full assessment of failure in slab elements. With appropriate consideration of equilibrium and kinematic approaches [13], it should be possible to generalise the findings from this work to other structural and loading configurations. 


\section{Experimental Programme}

A total of thirteen ambient tests were conducted on lightly reinforced concrete (LRC) strips with a view to: (i) gain a greater understanding of the mechanisms dominating the ultimate behaviour; (ii) assess and quantify the key parameters influencing the response; and (iii) provide the necessary information to validate and calibrate the analytical models. To this end, several important geometric and material properties have been varied so that their effect could be examined. Tests carried out to characterise the material properties for steel and concrete are firstly described below, followed by a detailed account of the idealised member tests.

\subsection{Material properties}

In order to examine the influence of the specific properties of steel on the behaviour, several reinforcement configurations, providing a range of material characteristics, were employed in the experimental study. Four types of reinforcement were considered, namely: (i) plain bars with a diameter of $6 \mathrm{~mm}$ (P6); (ii) deformed bars with a diameter of 6mm (D6); (iii) deformed bars of $8 \mathrm{~mm}$ diameter (D8); and (iv) A142 welded mesh consisting of $6 \mathrm{~mm}$ deformed bars spaced at 200mm centres (M6). At least three tensile tests were carried out for each type, in accordance with EN ISO 15630-1 [12]. The tests were conducted using an Instron testing machine, operating in displacement control at a rate of $4 \mathrm{~mm} /$ minute. A carefully-selected extensometer was employed to measure extension up to fracture of the bar, which enabled a full representation of the stress-strain response over a gauge length of $100 \mathrm{~mm}$.

The key mechanical characteristics resulting from the tensile reinforcement tests are summarised in Table 1 where $f_{s y}$ and $f_{s u}$ are the yield and ultimate strengths, respectively, and $\varepsilon_{s u}$ is the corresponding ultimate strain, measured through the extensometer. In terms of the reinforcement categories used in Eurocodes and other guides, the values given in Table 1 indicate that D6, M6 and D8 fall within the definition of Class 'A' reinforcement while P6 satisfies the requirements of Type ' $\mathrm{C}$ '. The plain bars were hot-rolled and hence $f_{s y}$ was easily distinguishable in the stress-strain response. In contrast, the other reinforcement-types were cold-worked and therefore displayed a more continuous constitutive relationship. Accordingly, the yield point was defined as the stress corresponding to a permanent strain of $0.2 \%$. The values given in the table are the average obtained from at least three specimens for each type of bar. The coefficient of variation was lower than 0.03 for both $f_{s y}$ and $f_{s u}$ and lower than 0.06 for $\varepsilon_{s u}$ in all cases. 


\subsection{Idealised member tests}

A schematic of the testing arrangement is illustrated in Fig. 1, and a general view of the testing arrangement is shown in Fig. 2. The specimens were supported vertically on rollers and hence were free to move both axially and rotationally at the two ends. Loading was applied at the middle of the specimen through closely spaced points to simulate mid-span loading. This was preferred to a single point load to avoid interfering with the wide crack that typically occurred at mid-length. A hydraulic actuator, operating in displacement control, was used in all cases. In each test, the displacement was gradually increased until failure occurred, typically by fracture of the reinforcement, which was accompanied by a significant reduction in load capacity.

This paper focuses on the results from a series of thirteen tests, within which the geometric characteristics related to length, width and depth were varied, together with the reinforcement type and configuration. The details of each specimen are described in Table 2 which gives the half-length $(L)$, width $(b)$, depth $(h)$ and reinforcement ratio $(\rho)$. Also included in the table is the effective depth of the reinforcement from the compressive face $\left(d_{s}\right)$, as well as the compressive $\left(f_{c}^{\prime}\right)$ and tensile $\left(f_{c t}\right)$ strength of concrete. The compressive strength was determined by crushing cubes $(100 \mathrm{~mm})$ on the day of testing (generally after 28 days) whereas an approximate tensile strength was obtained by completing 'Brazilian tests' on cylinders (4" diameter and 10" height). Both the compressive and tensile strengths were determined in accordance with EN 12390, Parts 3 and 6, respectively [13, 14]. The reinforcement was positioned at mid-depth in each case. An initial crack was precipitated in the specimens by introducing a thin film at mid-length extending $10 \mathrm{~mm}$ through the depth from the bottom fibre. Predefining the location of the initial crack facilitates instrumentation as well as comparison with numerical models, and has no notable influence on the behaviour.

The ultimate behaviour depends on a number of reinforcement characteristics, particularly those related to reinforcement ratio $(\rho)$ and bond stress $\left(\tau_{b}\right)$; therefore, most of the tests were designed to examine these effects. To this end, the bond strength was inherently varied within the test programme by utilising different bar-types, thus providing a realistic assessment of the prevalent characteristics. The test results also provide a means of calibrating the effective bond strength implemented in the analytical models, as discussed later. 
Fig. 3 illustrates the load-deflection response for each test containing: (a) P6, (b) D6, (c) M6, (d) D8. A large amount of data was obtained through the measurement of displacements, loads and strains during the tests, but emphasis will be placed herein on the load and displacement corresponding to failure. The three tests incorporating internally-gauges bars (UR11-13) are discussed subsequently in more detail in a separate section. The behaviour of strips is illustrated in Fig. 4a which provides a view of the deformed shape at large levels of displacement. Depending on the reinforcement ratio and the type of bar, the specimens exhibited either a single crack at mid-length (as illustrated in Fig. 4b) or multiple cracking (as shown in Fig. 4c). The pattern of cracking has a direct implication on the failure deformation, as discussed later on. For the purpose of the discussions presented in this study, the failure displacement, $U_{f, t e s t}$, is defined as the point at which the ultimate load carrying capacity drops by $10 \%$; i.e. from ultimate load $\left(F_{p, t e s t}\right)$ to failure load $\left(F_{f, t e s t}\right)$.

Table 3 summarises the main experimental results corresponding to $F_{p, \text { test }}, F_{f, \text { test }}$ and $U_{f, \text { test }}$. The theoretical yield and ultimate capacities $\left(F_{y}\right.$ and $\left.F_{u}\right)$, based on conventional sectional analysis for beams in flexure, are also given in the table. As discussed previously, the first crack occurred at the mid-span and following this, as the load increased, additional flexural cracks developed in some specimens, as illustrated in the views shown in Fig. 4. The degree of cracking was dependant on the ratio and type of reinforcement, as expected. Accordingly, Table 3 also indicates the number of cracks that formed in each specimen during testing. From the data provided in the table, and with reference to Fig. 3, the load carrying capacity was related to the reinforcement ratio and strength. As expected, this is broadly in agreement with the theoretical yield capacity, although localised concrete effects and variability of idealised material properties can cause some discrepancy. On the other hand, it is clear that the specimens with P6 reinforcement, which have a characteristically low strength, were the most ductile. This is a result of the combination of the high ultimate strain of the reinforcement coupled with the relatively low bond stress for this type of bar. A more detailed analysis of the results is discussed in the following sections, by assessing the influence of a number of salient parameters on the ultimate response. As noted before, the strain results from the specimens incorporating internally-gauges bars are discussed separately thereafter.

\subsubsection{Type of reinforcement}

With reference to the load-displacement plots in Fig. 3, it is evident that the specimens incorporating P6 reinforcement, which was hot-rolled, reached comparatively higher failure 
displacements than those comprising cold-worked bars. As noted before, in terms of capacity, members reinforced with D6, M6, D8 demonstrated considerably higher load-carrying capacity than those with P6, largely due to the higher strength of steel material. All of the tests failed when the steel reinforcement reached its tensile capacity and fractured across a full depth failure crack. This was typically accompanied by a sudden reduction in load.

\subsubsection{Member length}

The effect of member length on the behaviour is illustrated by comparing UR3 and UR6 (Fig. 3a) for which the spans where $1000 \mathrm{~mm}$ and $1400 \mathrm{~mm}$, respectively. As expected, the sustained vertical load was comparatively higher for UR3, largely in inverse proportion to the length. Both members developed a single crack across the mid-span and the failure displacement increased from $125 \mathrm{~mm}$ in UR3 to $175 \mathrm{~mm}$ in UR6 which is in proportion to the respective lengths. The influence of specimen length is illustrated further by examining the response (in Fig. 3c) of UR1 and UR9 which were also identical apart from length. The crack formation was similar in both specimens, with the development of three full-depth cracks. As with UR3 and UR6, the ratio in failure load between UR1 and UR9 was largely in inverse proportion to the increase in length. Clearly, there is also a direct relationship between the member length and the corresponding failure displacement according to the level of strain concentration in the steel. It is important to note however, that this conclusion is based on the crack formations being identical in the specimens considered. A greater degree of cracking would result in an increase in member ductility, thereby delaying ultimate failure, as discussed further in subsequent sections of this paper.

\subsubsection{Reinforcement ratio}

The effect of the reinforcement ratio $(\rho)$ on the behaviour is examined by assessing the responses of UR4 and UR8, as depicted in Fig. 3b. UR4 had a relatively low $\rho$ of $0.24 \%$ whilst UR8 had a higher ratio of $0.52 \%$. As expected, UR8 exhibited a greater load capacity than UR4, with $F_{p \text {,test }}$ increasing from $5.0 \mathrm{kN}$ in UR4 to $9.7 \mathrm{kN}$ in UR8. Specimen UR4 had a lower failure displacement of about $40 \mathrm{~mm}$, in comparison with approximately $60 \mathrm{~mm}$ for UR8. An increase in $\rho$ can lead to a greater degree of cracking, which was the case in UR8 as indicated in Table 3. This has the effect of relieving the strain concentration in the reinforcement, thereby delaying failure. The increase in failure displacement in UR8, compared to UR4, is a direct consequence of the greater degree of cracking that developed in this specimen. 


\subsubsection{Member depth}

The influence of cross-sectional depth is examined by comparing UR4 and UR5 which had respective depths of $60 \mathrm{~mm}$ and $40 \mathrm{~mm}$. The reinforcement area was identical in both specimens, thereby resulting in a higher reinforcement ratio of $0.35 \%$ in UR5 in comparison with $0.24 \%$ in UR4. It can be observed in Fig. $3 b$ that the capacity of UR5 is lower than that of UR4, as expected, owing to the reduced bending capacity. On the other hand, as indicated in Table 3, the failure deflection was significantly greater than that in UR4. This is mainly because UR5 had a greater reinforcement ratio than UR4 and hence developed more cracks. Further verification of these trends is obtained by assessing UR11, UR12 and UR13, each of which contained identical reinforcement arrangements and over- all depths of $60 \mathrm{~mm}, 90 \mathrm{~mm}$ and $120 \mathrm{~mm}$, respectively. As previously discussed, a relative increase in member depth causes a significant enhancement of the load-carrying capacity whereas failure occurs at a relatively lower level of deflection. This is because less cracking occurs and the steel reinforcement experiences greater strain concentrations.

The experimental results and observations discussed above have ascertained the influence of a number of salient parameters on the ultimate behaviour. Most of the material and geometric characteristics discussed above are inter-related. Accordingly, for a rational examination of failure, the relative influence of these parameters must be appropriately accounted for and quantified through reliable analytical models. Evidently, the bond strength between the steel and the concrete in the crack region, and the consequent effect on strain localisation in the steel reinforcement, has a direct effect on the deformation capacity of lightly reinforced concrete members. In order to enable a more detailed investigation of these local effects, three of the test specimens were heavily instrumented with strain gauges along the length, and the strain results are discussed in the following section.

\subsection{Reinforcement strains in Tests UR11-UR13}

Specimens UR11-UR13 were reinforced with $3 \times 8 \mathrm{~mm}$ D8 bars in an identical arrangement, although the overall depth $(h)$ varied between $60-120 \mathrm{~mm}$. Importantly, the central bar in each test was instrumented with 25 strain gauges along the length within a specially-milled duct, whist the remaining bars were solid. This enabled a direct assessment of the strain and bond distribution along the member length. The machining and gauging was conducted at Durham University using a specialist technique [15] which is described in the following section. The specimens were then cast and tested at Imperial College. 


\subsubsection{Instrumentation layout}

Each instrumented reinforcing bar was fabricated by milling two identical bars down to halfsize and then machining a groove along the length of each (Fig. 5a). This duct measured $2.5 \mathrm{~mm}$ wide and $1.25 \mathrm{~mm}$ deep in both segments. The strain gauges and associated wiring were accommodated within this groove, as shown in Fig. 5b, before the two halves were glued together using an epoxy resin. From the outside, the bars had the appearance of a normal reinforcement but with the lead wires coming out at the ends. It has also been previously shown [15] that the bond-slip relationship between the steel and surrounding concrete is unaffected by the bar alterations.

Each bar was $1650 \mathrm{~mm}$ in length and contained 25 gauges, the positions and labels of which are shown in Fig. 6. Adjacent gauges were positioned along alternate halves of the bar and an identical gauge layout was adopted in all three tests. More closely-spaced strain gauges were placed near the central crack region in order to provide detailed information on the distribution of bond stresses in this area. The reinforcing bars were $250 \mathrm{~mm}$ longer than the test specimens and therefore protruded at either end, in order to protect the wires during casting.

\subsubsection{Strain gauge results}

The load-deflection response of each unrestrained strip test was presented earlier. This section focuses on presenting and discussing the strain gauge results from Tests UR11-UR13. To this end, the distribution of steel strain along each instrumented bar, at various levels of vertical displacement, is presented in Figs. 7, 8 and 9 for UR11, UR12 and UR13, respectively. Also included in the figures are views of the crack pattern corresponding to each test. It is important to note that the gauges were only capable of reading until about $2.5 \%$ strain, after which the measurement became unreliable. This is particularly relevant in the central region of the strips (at about $700 \mathrm{~mm}$ ) as the strain in this area typically reached $2.5 \%$ at a relatively early stage. In spite of this, the figures clearly show the concentration of strain in the centralcrack region. Although there is a general reduction in the level of strain further away from the central crack, local peaks occur at specific locations (as shown in Figs. 7b, 8b and 9b). At these locations, which correspond to identifiable cracks, the applied stress is transferred from the concrete to the reinforcement causing a local increase in the steel strain. 
As discussed previously, the level of cracking in each specimen and the consequent effect on failure, was directly related to the depth and reinforcement ratio; accordingly, the thinnest member (UR11) developed the largest number of cracks and failed at the greatest deflection. Equally, comparison of Figs. 8a and 9a indicates that the steel strain was, as expected, most concentrated in UR13 and hence, this member failed at a relatively low level of displacement. Further examination of the strain localisation effects is carried out as part of the comparison with analytical studies in subsequent sections.

\section{Analytical Modelling}

The experimental results presented in the previous section furnished direct information on the relative influence of a number of geometric and material parameters on the ultimate response of simply supported strip elements representing idealised slab components. In order to provide further insight into the behaviour, and to enable quantification of the response for the purpose of future design studies, there is a need for suitable analytical models that are validated and calibrated against experimental results and detailed numerical simulations. To this end, an analytical approach that represents the response of lightly-reinforced members modified and utilised herein to predict the behaviour of the idealised members considered in this study. The solution procedure was firstly developed for restrained slab strips and subsequently extended to deal with full slab elements [9-11]. The approach enables the estimation of the deformation and load levels corresponding to failure, with due account of main geometric and material characteristics including the important influence of bond-slip. The following section provides a description of this simplified analytical approach. A nonlinear finite element model, which was used for further detailed analysis of the behaviour, is also described.

\subsection{Simplified analytical model}

As noted before, the simplified analytical model is adapted from a previous model developed for restrained members $[9,10]$. The model represents the post-cracking response of lightlyreinforced concrete member, as shown in Fig. 10, and predicts the level of load and deflection corresponding to failure by fracture of the reinforcement. It should be noted that the model applies to both ambient and elevated temperature conditions. Whilst experimental validation was only carried out for ambient conditions in this study, there is clearly a need for further experimental verification under elevated temperature. 
The following simplifying assumptions are considered in the modified model utilised in this study:

(i) a single crack forms at mid-span. This has been shown to be a conservative assumption in terms of failure prediction [9];

(ii) the beam is simply supported at the level of the reinforcement; neither axial nor rotational restraint is provided;

(iii) the shear force at the supports is transferred fully to the concrete and hence bond-slip is neglected in this region;

(iv) Plane sections of the concrete section remain plane, in accordance with the Euler-Bernoulli hypothesis, hence transverse shear deformation is ignored;

(v) bond is idealised as a rigid-plastic relationship and is characterised by the bond strength $\left(\tau_{b}\right)$;

(vi) the beam has a rectangular cross-section with a single layer of reinforcement;

(vii) temperature varies linearly over the cross-section with a gradient, $\nabla t$;

(viii) steel strains and bond-slip deformations vary monotonically.

The model is formulated on the basis of symmetry about the mid-span, hence half of the beam is considered in a local reference system as illustrated in Fig. 11. Depending on the combination of loading, geometry and material properties, the half-span $L$ consists of two regions, namely the 'bond-slip' and the 'no bond-slip'. The mechanical response of the steel is represented using the commonly-employed Ramberg-Osgood material model which, with thermal strain included, relates stress $\left(f_{s}\right)$ to strain $\left(\varepsilon_{s}\right)$ according to:

$$
\varepsilon_{s}=\frac{f_{s}}{E_{s}}+a_{s} f_{s}^{n_{s}}+\alpha_{s} t_{s}
$$

where $E_{s}$ is Young's modulus; $a_{s}$ and $n_{s}$ are two parameters which influence the elasto-plastic response; and $t_{s}$ and $\alpha_{s}$ are the temperature and coefficient of thermal expansion for steel.

It is also assumed that the concrete stiffness varies linearly throughout the section due to the temperature gradient. Therefore, the following explicit relationships can be derived for the axial rigidity $\left(E_{c} A_{c}\right)$, the bending rigidity $\left(E_{c} I_{c}\right)$ and the axial/bending interaction rigidity $\left(E_{c} Y_{c}\right)$ :

$$
E_{c} A_{c}=\frac{b h}{2}\left[E_{c b}+E_{c t}\right]
$$




$$
\begin{aligned}
& E_{c} I_{c}=\frac{b h}{12}\left[E_{c b}\left(h^{2}-4 h d_{s}+6 d_{s}{ }^{2}\right)+E_{c t}\left(3 h^{2}-8 h d_{s}+6 d_{s}{ }^{2}\right)\right] \\
& E_{c} Y_{c}=-\frac{b h}{6}\left[E_{c b}\left(h-3 d_{s}\right)+E_{c t}\left(2 h-3 d_{s}\right)\right]
\end{aligned}
$$

where $E_{c t}$ and $E_{c b}$ are the top and bottom fibre concrete stiffness, respectively, as influenced by temperature. Further information on the derivation of these expressions can be found in Izzuddin and Elghazouli [9].

As stated before, and shown in Fig. 10, $L$ is divided into two regions according to whether or not bond-slip occurs. The contributions of the concrete and steel to the overall cross-sectional response are established separately for each region. Accordingly, the strain $\left(\varepsilon_{a n}\right)$ and curvature $\left(\kappa_{a n}\right)$ in the steel and the concrete within the 'no-bond' region can be calculated, as a function of the distance from mid-span $(x)$, as

$$
\left[\begin{array}{cc}
E_{c} A_{c}+E_{s} A_{s} & E_{c} Y_{c} \\
E_{c} Y_{c} & E_{c} I_{c}
\end{array}\right]\left\{\begin{array}{c}
\varepsilon_{a n}(x)-\alpha_{c} t_{s} \\
\kappa_{a n}(x)+\alpha_{c} \nabla t
\end{array}\right\}=\left\{\begin{array}{l}
\frac{T_{s} h_{c}}{d_{s}}\left(1-\frac{x}{L}\right) \\
T_{s} h_{c}\left(1-\frac{x}{L}\right)
\end{array}\right\}
$$

where $A_{S}$ is the total area of reinforcement provided; $\alpha_{c}$ is the coefficient of thermal expansion for concrete; $T_{S}$ is the axial tensile force in the steel bar at the crack face; and $h_{c}$ is the assumed distance of the contact point from the level of the reinforcement (typically equal to $d_{s}$ ). The strain $\left(\varepsilon_{a}\right)$ and curvature $\left(\kappa_{a}\right)$ in the concrete in the bond-slip region can also be calculated as a function of $x$, from the following expression:

$$
\left[\begin{array}{ll}
E_{c} A_{c} & E_{c} Y_{c} \\
E_{c} Y_{c} & E_{c} I_{c}
\end{array}\right]\left\{\begin{array}{c}
\varepsilon_{a}(x)-\alpha_{c} t_{s} \\
\kappa_{a}(x)+\alpha_{c} \nabla t
\end{array}\right\}=\left\{\begin{array}{l}
n \pi \varphi \tau_{b} x-T_{s} \\
T_{s} h_{c}\left(1-\frac{x}{L}\right)
\end{array}\right\}
$$

where $n$ refers to the number of bars in the cross-section and $\varphi$ is the reinforcement diameter. The stress in the steel $\left(f_{s}\right)$ within the bond-slip region at a position $x$ can be determined from:

$$
f_{s}(x)=\frac{T_{s}-n \pi \varphi \tau_{b} x}{A_{s}}
$$

while the corresponding steel strain, $\varepsilon_{\mathrm{s}}(x)$, can be obtained by applying Eq. (1). The length of bar experiencing bond-slip, $x_{d}$, is determined as the location at which the steel stress in the two regions become identical, leading to: 


$$
x_{d}=\frac{T_{s}-A_{s} f_{a n}}{n \pi \varphi \tau_{b}}
$$

where $f_{a n}$ is the stress in the steel in the no-slip region obtained from $\varepsilon_{a n}$ of Eq. (5) according to Eq. (1). The extension of steel $\left(\Delta_{s}\right)$ and the shortening of the concrete $\left(\Delta_{c}\right)$ along the thermally-curved reference line, as well as the local rotation of the concrete at the crack-face $\left(\vartheta_{c}\right)$, can hence be obtained from:

$$
\begin{aligned}
& \Delta_{s}=\int_{0}^{x_{d}} \varepsilon_{s}(x) d x+\int_{x_{d}}^{L} \varepsilon_{a n}(x) d x \\
& \Delta_{c}=-\int_{0}^{x_{d}} \varepsilon_{a}(x) d x+\int_{x_{d}}^{L} \varepsilon_{a n}(x) d x \\
& \vartheta_{c}=\int_{0}^{x_{d}}\left(1-\frac{x}{L}\right) \kappa_{a}(x) d x+\int_{x_{d}}^{L}\left(1-\frac{x}{L}\right) \kappa_{a n}(x) d x
\end{aligned}
$$

The unrestrained axial pull-in due to thermal bowing, $\delta_{c 0}$, is:

$$
\delta_{c 0}=\frac{\vartheta_{t 0}^{2} L}{6}
$$

in which $\vartheta_{t 0}$ is the local rotation, at the crack location, due to thermal curvature, given by:

$$
\vartheta_{t 0}=\frac{\left(-\alpha_{c} \nabla t\right) L}{2}
$$

In enforcing compatibility between the two symmetric halves of the member (Figs. 10 and 11 ), it is assumed that the reinforcement has negligible bending resistance, thus stretching in a horizontal straight line across the mid-span crack. With reference to Fig. 12, the vertical deflection can be obtained from the steel and concrete deformations determined previously

$$
U=\left(\frac{\Delta_{\mathrm{s}}+\Delta_{\mathrm{c}}}{h_{c}}+\vartheta_{c}\right) \times\left(L-\delta_{c}+\Delta_{\mathrm{s}}+\Delta_{\mathrm{c}}\right)
$$

where $\delta_{c}$ is the axial shortening of the concrete obtained from:

$$
\delta_{c}=\delta_{c 0}+\Delta_{\mathrm{c}}
$$


Prior to calculating the corresponding load, it is necessary to establish $L_{2}$ which is the new horizontal component of the length after pull-in, according to Fig. 11, given by:

$$
L_{2}=\sqrt{\left(\mathrm{L}-\delta_{\mathrm{c} 0}+\Delta_{\mathrm{s}}\right)^{2}-U^{2}}
$$

Finally, half of the total applied load $(P)$ at a deflection $U$ is determined as:

$$
P=\frac{T_{s} h_{c}}{L_{2}}
$$

Most importantly, in addition to the overall response, the deformation and load levels corresponding to the attainment of ultimate strain in the steel can also be obtained from Eqs. (14) and (17), respectively, hence providing a prediction of the failure limit associated with reinforcement fracture.

The above formulations have been implemented in a Maple v12.0 worksheet [16] as the symbolic computational interface facilitates the necessary solution procedure. The applicability of the model is examined in subsequent sections, by comparison against the experimental results as well as detailed numerical simulations. Additionally, reduced expressions, based on further simplification of the analytical model, are proposed later on in this paper for the purpose of practical design oriented assessments.

\subsection{Finite element model}

To provide further examination and verification of the behaviour, the nonlinear finite element analysis program ADAPTIC [17] was also used to simulate the response of the members. The program accounts for material and geometric nonlinearities, and has been extensively validated for various types of structure and loading conditions [e.g. 18, 19]. A twodimensional displacement-controlled static analysis was employed. One-dimensional beamcolumn elements (cbp2) which adopt a cubic shape function and a fibre approach [17, 19] are employed for modelling the members. Based on a mesh sensitivity study, the concrete and steel components within each member were modelled using 150 equal-length elements (i.e. $9.33 \mathrm{~mm}$ or $6.66 \mathrm{~mm}$ each in length for specimens of length 1400 or $1000 \mathrm{~mm}$, respectively). Also, due to the highly nonlinear interactions between steel and concrete in the presence of bond-slip, this fine level of discretisation was necessary in order to achieve convergence. The steel and concrete components were connected at their coincident nodes with 2D joint elements (jel2) representing the bond-slip characteristics of the reinforcement. These elements have a user-defined axial stiffness and were assumed to be rigid in both shear and rotation. 
The steel material was modelled using a multi-surface plasticity model (stl2) which enables a faithful representation of the nonlinear characteristics of the constitutive relationship. This is illustrated in Fig. 13 which, for example, depicts the accurate stl 2 representation of the steel material compared to the experimentally-measured stress-strain relationship for P6 bars. On the other hand, the concrete was represented using a uniaxial constant confinement concrete model (con2), illustrated in Fig. 14, which requires knowledge of the compressive strength, tensile strength and crushing strain. A single crack was introduced in the finite element simulations corresponding for consistency with the assumption of the simplified analytical model. To achieve this, the concrete element located at mid-span was assigned a negligible tensile strength relative to the rest of the member. Comparative assessments of the finite element simulations against the results of the tests as well as the simplified analytical model are presented in the following section.

\section{Comparative Assessments}

This section compares the experimental results to the predictions of both models, for the different material and geometric parameters assessed in the experimental programme. Particular emphasis is given to examining the failure conditions.

\subsection{Load-deflection response}

Fig. 15 presents the relationships between the total load applied and the mid-span deflection for each specimen containing (a) P6, (b) D6, (c) M6 and (d) D8. The numerical curves are plotted up to the attainment of ultimate strain in the steel across the full-depth crack at midlength; hence, the final point corresponds to failure by reinforcement fracture. The failure deflections obtained from the simplified analytical model, $U_{f, S A M}$, and the finite element model, $U_{f, F E M}$, are included in Table 3, together with the corresponding test values, $U_{f, \text { test }}$. The ratios of these values with respect to the corresponding experimental failure deflections are also included in Table 3.

As illustrated in the comparative plots in Fig. 15, both the analytical and numerical simulations are able to capture the main characteristics of the experimental load-displacement response. Apart from the depiction of initial stiffness and yield point, both the numerical and analytical procedures predict the failure deflection within an accuracy of about $10 \%$, as illustrated in Table 3, with the exception of UR1 and UR3 for which the difference reached $11 \%$ and $17 \%$, respectively. Other discrepancies in the load-deflection response are attributed 
to modelling idealisations, in particular those related to the material representation. To this end, it should be noted that discrepancies with the experimental load ${ }^{\perp}$ deflection curves in the final stage prior to failure occur since material softening is not included in the analysis.

The analytical and numerical predictions are clearly highly dependant on a realistic representation of the material properties, including the bond strength between the steel and the concrete. The test results therefore provide a means for direct calibration of the idealized bond strength that needs to be employed in the model. As discussed previously, the bond-slip behaviour is idealised in both the analytical and numerical models as a rigid-plastic relationship. On this basis, representative values of effective bond strength $\left(\tau_{b}\right)$ were determined to be in the range of $0.8-0.9 \mathrm{~N} / \mathrm{mm}^{2}$ for P6, 1.2-1.3 N/mm ${ }^{2}$ for D6 and D8 and 1.7$1.8 \mathrm{~N} / \mathrm{mm}^{2}$ for M6. Clearly, due to the different loading and behavioural conditions, these values are considerably lower than those measured in conventional pull-out bond tests. It is also important to recall that a single crack is assumed in the analytical model, and enforced in the finite element simulation. Consequently, the bond strength employed implicitly accounts for the resulting influence of any additional cracks that develop.

Overall, the comparisons presented in this section show that the proposed simplified analytical model is capable of predicting the load-displacement response as well as the deflection and load levels corresponding to failure. The predictions are reasonably accurate provided that the material properties, particularly those related to the bond-slip characteristics and the post-yield behaviour of steel, are realistically represented. To this end, in the subsequent section, the bond idealisation employed in the SAM is compared to the actual bond distribution along the member, which can be derived from the steel strain data acquired in Specimens UR11-UR13. Following this, the sensitivity of the simplified analysis to the assumed steel constitutive relationship, as well as to the level of bond strength adopted, is investigated.

\subsection{Bond stress distribution}

The simplified analytical model assumes that a single crack forms at the mid-span of the beam and accordingly, calculates the level of strain that occurs in the reinforcement at this location, for a given bond strength. This section examines the validity of this representation by examining the steel strain readings acquired during tests UR11-13. As an example, Fig. 16 depicts the strain gauge measurements immediately adjacent to the central crack for UR13 together with the corresponding SAM simulations. Evidently, the model provides very 
reasonable depictions. The strain increased significantly at approximately $10-15 \mathrm{~mm}$ deflection in both tests due to yielding of the reinforcement; this is realistically represented by the SAM.

In addition to the above comparison, it is possible to establish the bond strength distribution along the length of the bar based on the strain measurements in the reinforcement. The strain distributions depicted in Figs. 7a, 8a and 9a indicate that the variation in strain on either side of a crack is close to linear; this is in agreement with the findings of other studies [15]. Accordingly, the average bond stress between adjacent strain gauges can be calculated from the average change in stress over that interval. The bond stress distribution for each of the three tests at various levels of vertical deflection is presented in Fig. 17, together with the bond strength idealisation adopted in the corresponding simplified model analysis. For clarity, only the bar length which is instrumented with strain gauges (i.e. up to $920 \mathrm{~mm}$ as shown in Fig. 6) is illustrated. The analytical bonded-length shown in the figures corresponds to the prediction for $x_{d}$ at failure. Clearly, the model adaptation of the bond-slip relationship, which is based on a single-crack assumption, is rather different to the actual bond distribution which is dictated by the formation of cracks along the length. The experimental data shows that the bonded length expands with increasing deflection. On the other hand, the maximum bond strength in each test (i.e. about 4,7 and $9 \mathrm{~N} / \mathrm{mm}^{2}$ for UR11, UR12 and UR13, respectively) develops from a very early stage in the response. This is expected given that maximum bond occurs at relatively low levels of slip in an actual bond-slip relationship.

The peaks in the plots in Fig. 17 are indicative of both full-depth cracks, as shown in Fig. 4, and also of any internal cracks that may develop locally at the interface between the steel and the concrete. Throughout the response, the bond strength in UR11 is notably less than that in UR12 or UR13 owing to the reduced cover distance and greater level of cracking that occurred. It is clear that the depth of the section has an influence on: (i) the number of cracks that form, (ii) the concentration of strain in the reinforcement at the crack locations and (iii) the level of bond strength that develops between the steel and the concrete. Hence, owing to the combination of these inter-related parameters, the ductility expressed in terms of the failure defection is also affected by the member depth. This is in agreement with the findings presented earlier in this paper. 
Overall, the experimental findings discussed in this section have provided an insight into the concentration of strain, and consequent distribution of bond strength, that occurs in LRC members as they deform. Whilst several specimens exhibited multiple cracking, it is conservative to assume that a single crack forms as this leads to a higher concentration of strain and lower failure deflection. The following section provides additional analysis into the sensitivity of the prediction to the modelling idealisations adopted.

\subsection{Sensitivity studies}

This section provides additional assessment of the sensitivity of the failure prediction provided by the analytical model to: (i) the stress-strain representation for steel and (ii) the level of bond strength.

\subsubsection{Constitutive relationship of steel}

The constitutive relationship of steel, which can vary significantly depending on the type and grade of reinforcement used, has a direct influence on the behaviour. The deflection at which failure by reinforcement fracture occurs is directly related to the ultimate strain of steel. In addition, the post-yield strain-hardening has a significant influence on the ultimate behaviour as it has a direct effect on the ductility of the member. To illustrate this, the constitutive relationship for steel employed in the analysis of UR3 is varied as shown in Fig. 18a, while all other properties are unchanged. In the figure, the middle curve (K1) represents the actual relationship utilised in previous analyses. It is worth noting that the value of ultimate strain and the corresponding stress is kept the same in all three relationships.

The load-displacement response corresponding to the three steel models discussed above are shown in Fig. 18b, where the final point on the curve represents failure by reinforcement fracture. Although $\varepsilon_{s u}$ remains unchanged, failure is significantly delayed if the material exhibits relatively high strain hardening properties. This is owing to the lower level of strain concentration in the steel across the crack face, which leads to the attainment of higher deformation capacity. This behaviour is further demonstrated in Fig. 18c which shows the progression of the bond-slip length $x_{d}$, for all three cases. Although the ultimate slip length reached at failure is the same, it is mobilised at a relatively low level of deflection when strain hardening is insignificant, as in the case of the K2, resulting in an early failure. This illustrates clearly the importance of incorporating a faithful representation of the post-yield properties of steel in order to obtain a reliable prediction of failure. 


\subsubsection{Bond strength}

The bond strength between the steel reinforcement and the surrounding concrete is one of the most important parameters influencing the ultimate behaviour [9]. Bond is intrinsically related to the strain distribution along the length of the bar and also to the development of cracks. The bond properties can vary considerably depending on the type and surface condition of the reinforcement as well as the properties of concrete [20,21]. The influence of bond strength on the ultimate conditions is illustrated in Fig. 19 for the four different bar types employed in the tests (i.e. $6 \mathrm{~mm}$ plain, deformed and mesh reinforcement, as well as $8 \mathrm{~mm}$ deformed bars). Values of bond strength between 0.5 and $3 \mathrm{~N} / \mathrm{mm}^{2}$ are varied in the SAM analysis whilst retaining all other parameters. The specimens have similar geometrical properties to those in the following test specimens: UR1 (M6), UR4 (D6), UR6 (P6) and UR11 (D8).

As shown in Fig. 19, the failure deflection reduces non-linearly for each bar-type as the bond strength increases. Considering the members with the most ductile reinforcement (P6), a relatively high bond stress $\left(3 \mathrm{~N} / \mathrm{mm}^{2}\right)$ causes the member to fail at an early stage whereas a much lower bond $\left(0.5 \mathrm{~N} / \mathrm{mm}^{2}\right)$ results in a substantially larger failure deflection, as the bondslip length is much greater; this, in effect, reduces the concentration of strain in the steel and hence delays failure. This behaviour is also shown in members with other bar types; although the failure deflections are much lower in the strips with D6, M6 or D8 owing to the lower ductility of these bars. In general, it is clear that low bond strength is beneficial in terms of delaying failure, hence resulting in significantly enhanced member ductility. The sensitivity of the behaviour to the bond idealisation was also investigated by implementing a more complex bond-slip relationship in the model [20]. For brevity, this is not included herein as the analysis shows that the simple rigid-plastic assumption is capable of providing a reliable representation provided that adequately-calibrated bond strength values are adopted.

\subsubsection{Length of bond-slip region}

The importance of bond strength to the ultimate performance of axially unrestrained strip elements has been highlighted in the preceding sections, including the effect that $x_{d}$ has on the failure point. This section employs the finite element model to investigate the progression of the slip length as the vertical deflection increases. The extent of the slip length is inherently related to both the bond strength and the ductility of the reinforcement. A low bond generally leads to a relatively longer bond-slip length and hence the strain in the steel is spread over a greater distance and failure is consequently delayed. Furthermore, $x_{d}$ also tends to be 
relatively long for a comparatively ductile reinforcement, thereby causing a beneficial delay before failure occurs.

This is evident in Table 4 which gives the extension of $x_{d}$ in Specimen UR3, as a function of vertical deflection $U$, for three different values of $\tau_{b}$. For both of the lower bond values, the slip length extends to the full span of the member at relatively low levels of deflection, which significantly delays the attainment of ultimate strain in the steel. For a higher bond value of $1.2 \mathrm{~N} / \mathrm{mm}^{2}$, the bond-slip length is shorter resulting in greater strain concentration in the steel around the crack, leading to expedited failure. Clearly, in addition to the length itself, the rate at which $x_{d}$ progresses is related to the bond strength and is faster for relatively low values of bond.

\subsection{Reduced expressions}

From the above discussions, it is evident that the failure of lightly reinforced concrete members by reinforcement fracture is directly related to the concentration of strain which, in turn, is influenced by a number of important inter-related parameters. The most significant of these factors have been identified and comprise: the element length, or half-length as employed in the SAM $(L)$; the number of bars $(n)$; the bar diameter $(\varphi)$ and total crosssectional area of steel $\left(A_{s}\right)$; the strain-hardening characteristics of the reinforcement $\left(f_{s u}-f_{s y}\right)$; the ultimate strain of the steel $\left(\varepsilon_{s u}\right)$; and the bond strength $\left(\tau_{b}\right)$ between the steel and the concrete. This is in agreement with previous analytical studies which have been conducted at Imperial College [10]. Further illustration of the importance of these characteristics is provided in Fig. 20 which depicts the concentration of strain in the steel across the failure crack, defined as the ratio of ultimate strain $\varepsilon_{s u}$ to the average strain at failure $\varepsilon_{a v}$ against a non-dimensional parameter $\beta_{\varepsilon}$, within a practical parameter range. In the above, $\varepsilon_{a v}$ and $\beta_{\varepsilon}$ are determined as:

$$
\varepsilon_{a v}=\frac{\Delta_{\mathrm{s}}}{L}
$$

and

$$
\beta_{\varepsilon}=\frac{n \tau_{b} \varphi \pi L}{A_{s}\left(f_{s u}-f_{s y}\right)}
$$

The data set depicted in the figure represents the results generated from the simplified analytical model for members similar to those examined in the experimental programme, thus 
providing an illustrative range of geometric and material parameters. As shown in the figure, a linear relationship exists between the strain concentration $\left(\varepsilon_{u} / \varepsilon_{a v}\right)$ and the non-dimensional parameter $\beta_{\varepsilon}$. The strain concentration can reach very high values, with the corresponding average strain being comparatively low. The relationship given in Eq. 19 also reflects that a relatively high bond strength and/or low strain-hardening in steel would result in reduced ductility.

By employing an appropriate transformation between average strain and deflection, it is also possible to establish a direct relationship between the normalised failure deflection $\left(U_{f, \text { test }} / L\right)$ and a parameter $\Psi_{u}$, given by:

$$
\Psi_{u}=\frac{A_{s}\left(f_{s u}-f_{s y}\right)}{n \tau_{b} \varphi \pi} \times \frac{\varepsilon_{s u}}{h_{c}}
$$

The above equation only applies to members where the bonded length $x_{d}$ remains within the half-span L. However, in certain circumstances (e.g. when low bond exists and the reinforcement exhibits relatively good ductility properties) $x_{d}$ can extend to $L$. In this case, assessment of the length of the bond-slip region at failure is obtained from the following simplified expression:

$$
x_{d}=\frac{A_{s}\left(f_{s u}-\lambda f_{m c}\right)}{n \tau_{b} \varphi \pi}
$$

where $f_{m c}$ is the stress in the steel reinforcement when the moment capacity of the section is reached and $\lambda$ is a constant related to the fabrication process of the steel. For the bar types examined in this paper, the recommended empirical values of $\lambda$ are 0.5 for cold-worked bars and 0.25 for hot-rolled bars. Hence, if $x_{d} \geq L$, the dimensionless parameter $\Psi_{u}$ is given by:

$$
\Psi_{u}=\frac{1}{2 h_{c}}\left(\frac{A_{s}\left(f_{s u}-f_{s y}\right)\left(\varepsilon_{s u}-\varepsilon_{s y}\right)}{n \tau_{b} \varphi \pi}+L \varepsilon_{s y}\right)
$$

where $\varepsilon_{s y}$ is the yield strain of the reinforcement. From Eq. (19), it can be concluded that the relationship between $\Psi_{u}$ and $U_{f} / L$ has a slope of about $2 / 3$, which is further confirmed by applying Eqs. (20) and (22) to the corresponding experimental data, as illustrated in Fig. 21. The bond-slip length in members containing P6 bars (which had both low bond and relatively high ductility) was limited to $L$; therefore Eq. (22) is applied for these specimens. Conversely, $x_{d}$ remained within $L$ for the remaining test members and hence, Eq. (20) is applicable. On the other hand, the failure deflection can be derived as follows: 


$$
\begin{array}{ll}
U_{f, c a l c}=\frac{2 L}{3 h_{c}}\left(\frac{A_{s}\left(f_{s u}-f_{s y}\right) \varepsilon_{s u}}{n \tau_{b} \varphi \pi}\right) & \text { if } x_{d}<L \\
U_{f, c a l c}=\frac{L}{3 h_{c}}\left(\frac{A_{s}\left(f_{s u}-f_{s y}\right)\left(\varepsilon_{s u}-\varepsilon_{s y}\right)}{n \tau_{b} \varphi \pi}+L \varepsilon_{s y}\right) & \text { if } \quad x_{d} \geq L
\end{array}
$$

$U_{f, \text { calc }}$ has been determined for each of the laboratory experiments that failed by reinforcement fracture, and the predictions are given in Table 3. It is evident that the simplified calculated values give reasonable estimations of the predicted failure deflection for each of the test specimens. It is also noteworthy that Eq. (23) is based on the assumption that a single crack will occur at the mid-span of the member. Accordingly, the expression would tend to underestimate the failure deflection if multiple cracking occurs. As discussed before, this aspect of behaviour was also observed in the experimental investigation in which, depending on the type of bars used and the reinforcement ratio, some members exhibited multiple cracking. This is implicitly accounted for through the bond strength values adopted.

\section{Elevated Temperature Response}

Although the experimental programme discussed in this paper has focussed on ambient response, a direct application of the results is for assessing the behaviour of members under fire conditions. Subject to experimental validation, which has yet to be competed, the analytical model described in this paper can be employed to assess the elevated temperature response of slab members. The model accounts for the effect of elevated temperature, including the variation in material properties as well as thermal expansion and thermal curvature. For brevity, this behaviour is not discussed in great detail herein, and further information can be found elsewhere [20]. The influence of the temperature-dependant material and geometric effects has been analysed and the reduced expressions derived previously for the ambient-temperature failure deflection (Eq. (23)) have been extended to account for elevated temperature effects such as increased reinforcement ductility and thermal expansion. Subject to further experimental validation under realistic elevated temperature conditions and for members of various forms and boundary conditions, relationships of this form can be used as a basis for implementing appropriate failure criteria in practical analytical and design procedures. 


\section{Conclusions}

This paper has presented experimental and analytical studies into the ultimate response of strip elements representing isolated slab components. Particular attention has been given to assessing the underlying mechanisms leading to failure by rupture of the reinforcement. To this end, a series of thirteen ambient tests were conducted in order to examine the influence of a range of material and geometric properties on the ultimate behaviour. This, in turn, enabled the most salient parameters, such as the steel properties and the bond strength, to be identified and assessed.

A simplified analytical model for representing the response of lightly reinforced members, as well as predicting the deflection and load levels corresponding to failure, was considered in this paper. The model was validated and calibrated by comparison against the test results as well as more detailed nonlinear finite element simulations. Although the focus in this paper was on the behaviour of isolated strip elements, the proposed model represents a significant and necessary step towards understanding and quantifying the key parameters that influence the ultimate behaviour of floor slabs. To this end, it was shown that the effective bond between the steel reinforcement and the strain-hardening characteristics of the reinforcement are two material parameters that have a significant influence on the ultimate behaviour. In particular, it was demonstrated that failure could be significantly delayed in the presence of relatively low bond-strength or comparatively high strain-hardening properties. Although beyond the scope of this paper, the analytical model is also applicable under elevated temperature conditions which was briefly discussed herein.

Simplified expressions were also derived based on the experimental and analytical findings of this study which capture the influence of the main material and geometric effects. They provide an evaluation of the strain and deflection levels corresponding to failure, which may be utilised in future numerical and design studies. With further experimental and analytical verification, covering other loading and boundary conditions, the work presented in this investigation can contribute to the provision of appropriate limiting criteria with a view to establishing more rational performance-based design provisions. 


\section{Acknowledgements}

The support provided by the Engineering and Physical Sciences Research Council (EPSRC) in the UK for the work described in this paper is gratefully acknowledged. The authors would also like to thank the technical staff of the structures laboratories at Imperial College London, particularly Mr. Trevor Stickland, for their assistance with the experimental work. The contribution of Dr. Richard Scott at Durham University is also gratefully acknowledged.

\section{References}

[1] Wang, Y.C., Lennon, T., and Moore, D.B. (1995). "The behaviour of steel frames subject to fire." Journal of Constructional Steel Research, 35:291-322.

[2] O’Connor, M. A., Kirby, B. R. and Martin, D. M. (2003), "Behaviour of a Multi-Storey Composite Steel Framed Building in Fire”. The Structural Engineer, 81(2): 27-36.

[3] Huang, Z., Burgess, I. W. and Plank, R. J. (1999). "Nonlinear analysis of reinforced concrete slabs subjected to fire.” American Concrete Institute Structural Journal, 96(1):127135 .

[4] Bailey, C.G. and Moore, D.B. (2000), "The structural behaviour of steel frames with composite floor slabs subject to fire. Part 1: Theory", The Structural Engineer, 78(11):19-27. [5] Bailey, C.G. and Moore, D.B. (2000), "The structural behaviour of steel frames with composite floor slabs subject to fire. Part 2: Design”, The Structural Engineer, 78(11):28-33. [6] Gillie, M., Usmani, A.S., and Rotter, J.M. (2001). “A structural analysis of the first Cardington test", Journal of Constructional Steel Research, 57: 581-601.

[7] Elghazouli, A. Y. and Izzuddin, B. A. (2001). "Analytical assessment of the structural performance of composite floors subject to compartment fires", Fire Safety Journal, 36: 769793.

[8] Lim, L., Buchanan, A. and Moss, P. (2003). "Experimental testing and numerical modelling of two-way concrete slabs under fire conditions", Journal of the Structural Engineering Society New Zealand, SESOC, pp12-26.

[9] Izzuddin, B. A. and Elghazouli, A. Y. (2004). "Failure of Lightly Reinforced Concrete Members under Fire - I: Analytical Modelling”, Journal of Structural Engineering, 130(1): 317.

[10] Elghazouli, A. Y. and Izzuddin, B. A. (2004). "Failure of Lightly Reinforced Concrete Members under Fire - II: Parametric Studies and Design Considerations", Journal of Structural Engineering, 130(1): 18-31. 
[11] Omer, E., Izzuddin, B. A. and Elghazouli, A. Y. (2006). "Failure assessment of simply supported floor slabs under elevated temperature, Structural Engineering International, 16: $148-155$.

[12] EN ISO 15630-1 (2002). "Steel for the reinforcement and prestressing of concrete - Test methods - Part 1: Reinforcing bars, wire rod and wire.” International Standards Organisation, Geneva, Switzerland.

[13] EN 12390 - 3 (2000). "Testing hardened concrete-Part 3: Compressive strength of test Specimens". European Committe for Standardization, Brussels.

[14] EN 12390 - 6 (2000). "Testing hardened concrete-Part 6: Tensile splitting strength of test specimens". European Committe for Standardization, Brussels.

[15] Scott, R.H. and Gill, P.A.T. (1987). Short term distributions of strain and bond stress along tension reinforcement. The Structural Engineer 65B(2): 39-43.

[16] Maple V12.0 (2008). Maple Waterloo Inc., Waterloo Ontario, Canada.

[17] Izzuddin B.A. (1991). "Nonlinear dynamic analysis of framed structures", PhD Thesis, Imperial College, University of London.

[18] Izzuddin, B. A., and Elnashai, A. S. (1993). "Eulerian formulation for large displacement analysis of space frames.' J. Eng. Mech., 119(3): 549-69.

[19] Izzuddin, B. A., and Elnashai, A. S. (1993). “Adaptive space frame analysis. Part II: A distributed plasticity approach.” Struct. Build. J., Proc. Inst. Civ. Eng., London, England, 99(3): 317-26.

[20] Cashell, K.A. (2009), "Failure assessment of floor slab systems under extreme loading conditions", PhD Thesis, Imperial College London.

[21] Cashell K.A., Elghazouli A.Y. and Izzuddin B.A., (2009). "Ultimate behavior of idealized composite floor elements at ambient and elevated temperature", Fire Technology, in press. 


\section{Tables}

Table 1: Steel reinforcement properties

\begin{tabular}{|c|c|c|c|}
\hline & $\begin{array}{c}\boldsymbol{f}_{\text {sv }} \\
\left(\mathbf{N} / \mathbf{m m}^{2}\right)\end{array}$ & $\begin{array}{c}\boldsymbol{f}_{\text {su }} \\
\left(\mathbf{N} / \mathbf{m m}^{2}\right)\end{array}$ & $\boldsymbol{\varepsilon}_{\text {su }}$ \\
\hline $\mathbf{P 6}$ & 252 & 330 & 0.203 \\
\hline $\mathbf{D 6}$ & 553 & 602 & 0.041 \\
\hline $\mathbf{M 6}$ & 552 & 589 & 0.025 \\
\hline $\mathbf{D 8}$ & 555 & 601 & 0.041 \\
\hline
\end{tabular}


Table 2: Specimen details

\begin{tabular}{|c|c|c|c|c|c|c|c|c|}
\hline TEST & $\begin{array}{c}L \\
(\mathrm{~mm})\end{array}$ & $\begin{array}{c}b \\
(\mathrm{~mm})\end{array}$ & $\begin{array}{c}h \\
(\mathrm{~mm})\end{array}$ & $\begin{array}{c}d_{s} \\
(\mathrm{~mm})\end{array}$ & Bar Type & $\begin{array}{c}\rho \\
(\%)\end{array}$ & $\begin{array}{c}f_{c}{ }^{\prime} \\
\left(\mathrm{N} / \mathrm{mm}^{2}\right)\end{array}$ & $\begin{array}{c}f_{c t} \\
\left(\mathrm{~N} / \mathbf{m m}^{2}\right)\end{array}$ \\
\hline UR1 & 500 & 600 & 60 & 30 & M6 & 0.24 & 29.9 & 2.2 \\
\hline UR2 & 500 & 600 & 60 & 30 & M6 & 0.24 & 29.9 & 2.2 \\
\hline UR3 & 500 & 600 & 60 & 30 & P6 & 0.24 & 29.9 & 2.2 \\
\hline UR4 & 700 & 600 & 60 & 30 & D6 & 0.24 & 31.9 & 2.1 \\
\hline UR5 & 700 & 600 & 40 & 20 & D6 & 0.35 & 31.9 & 2.1 \\
\hline UR6 & 700 & 600 & 60 & 30 & P6 & 0.24 & 47.7 & 3.1 \\
\hline UR7 & 700 & 540 & 60 & 30 & P6 & 0.52 & 47.7 & 3.1 \\
\hline UR8 & 700 & 540 & 60 & 30 & D6 & 0.52 & 47.7 & 3.1 \\
\hline UR9 & 700 & 600 & 60 & 30 & M6 & 0.24 & 40.4 & 2.4 \\
\hline UR10 & 700 & 600 & 60 & 30 & D6 & 0.24 & 40.4 & 2.4 \\
\hline UR11 & 700 & 480 & 60 & 30 & D8* & 0.52 & 31.9 & 2.5 \\
\hline UR12 & 700 & 480 & 90 & 45 & D8* & 0.35 & 31.9 & 2.5 \\
\hline UR13 & 700 & 480 & 120 & 60 & D8* & 0.26 & 31.9 & 2.5 \\
\hline
\end{tabular}

* special strip incorporating internally instrumented bars 
Table 3: Experimental data

\begin{tabular}{|c|c|c|c|c|c|c|c|c|c|c|c|c|c|}
\hline TEST & $\begin{array}{c}F_{y} \\
(\mathrm{kN})\end{array}$ & $\begin{array}{c}F_{u} \\
(\mathbf{k N})\end{array}$ & $\begin{array}{c}F_{p, t e s t} \\
(\mathbf{k N})\end{array}$ & $\begin{array}{r}F_{f, t e s t} \\
(\mathbf{k N})\end{array}$ & $\begin{array}{l}U_{f, t e s t} \\
(\mathbf{m m})\end{array}$ & $\begin{array}{c}\zeta= \\
F_{p, t e s t} / F_{u}\end{array}$ & No. cracks & $\begin{array}{c}U_{f, S A M} \\
(\boldsymbol{m m})\end{array}$ & $\frac{U_{f, S A M}}{U_{f, t e s t}}$ & $\begin{array}{c}U_{f, F E M} \\
(m m)\end{array}$ & $\frac{U_{f, F E M}}{U_{f, \text { test }}}$ & $\begin{array}{c}U_{f, c a l c} \\
(\mathrm{~mm})\end{array}$ & $\frac{U_{f, \text { calc }}}{U_{f, \text { test }}}$ \\
\hline UR1 & 6.39 & 6.74 & 6.41 & 5.77 & 28 & 0.95 & 3 & 25 & 0.89 & 27 & 0.96 & 25 & 0.89 \\
\hline UR2 & 6.39 & 6.74 & 5.73 & 5.16 & 25 & 0.85 & 2 & 25 & 1.00 & 27 & 1.08 & 24 & 0.94 \\
\hline UR3 & 3.01 & 3.62 & 2.95 & 2.66 & 125 & 0.82 & 1 & 128 & 1.02 & 125 & 1.00 & 132 & 1.06 \\
\hline UR4 & 4.37 & 4.76 & 5.01 & 4.51 & 40 & 1.05 & 5 & 37 & 0.93 & 37 & 0.93 & 39 & 0.97 \\
\hline UR5 & 2.84 & 3.09 & 3.16 & 2.84 & 63 & 1.02 & 8 & 62 & 0.98 & 64 & 1.02 & 64 & 1.01 \\
\hline UR6 & 2.05 & 2.46 & 1.91 & 1.72 & 175 & 0.78 & 1 & 178 & 1.02 & 180 & 1.03 & 187 & 1.07 \\
\hline UR7 & 4.02 & 5.31 & 4.62 & 4.16 & 200 & 0.87 & 1 & 192 & 0.96 & 190 & 0.95 & 213 & 1.06 \\
\hline UR8 & 9.04 & 9.96 & 9.72 & 8.75 & 60 & 0.98 & 9 & 57 & 0.95 & 59 & 0.98 & 64 & 1.06 \\
\hline UR9 & 4.40 & 4.64 & 4.81 & 4.33 & 35 & 1.04 & 3 & 35 & 1.00 & 36 & 1.03 & 35 & 1.00 \\
\hline UR10 & 5.96 & 6.48 & 6.02 & 5.42 & 35 & 0.93 & 5 & 41 & 1.17 & 40 & 1.14 & 41 & 1.17 \\
\hline UR11 & 7.36 & 8.57 & 6.91 & 6.22 & 54 & 0.81 & 10 & - & - & - & - & - & - \\
\hline UR12 & 12.46 & 14.47 & 12.33 & 11.09 & 25 & 0.85 & 5 & 26 & 1.04 & 26 & 1.04 & 23 & 0.91 \\
\hline UR13 & 17.04 & 19.78 & 19.76 & 17.78 & 16 & 1.00 & 3 & 16 & 1.00 & 15 & 0.94 & 16 & 0.97 \\
\hline
\end{tabular}


Table 4: Progression of $x_{d}$ for Specimen UR3

\begin{tabular}{|c|c|c|c|}
\hline $\begin{array}{c}\text { Level of } \\
\text { deflection, } \\
\boldsymbol{U} \\
\mathbf{( m m )}\end{array}$ & $\begin{array}{c}\tau_{\mathbf{b}}=\mathbf{0 . 6 N} / \mathbf{m m}^{2} \\
\boldsymbol{x}_{\boldsymbol{d}} \\
\mathbf{( m m )}\end{array}$ & $\begin{array}{c}\tau_{\boldsymbol{b}}=\mathbf{0 . 9 N} / \mathbf{m m}^{2} \\
\boldsymbol{x}_{\boldsymbol{d}} \\
\mathbf{( m m )}\end{array}$ & $\begin{array}{c}\boldsymbol{\tau}_{\boldsymbol{b}}=\mathbf{1 . 2 N} / \mathbf{m m}^{2} \\
\boldsymbol{x}_{\boldsymbol{d}} \\
(\mathbf{m m})\end{array}$ \\
\hline $\mathbf{0}$ & 0 & 140 & 0 \\
\hline $\mathbf{2 0}$ & 474.2 & 375 & 281 \\
\hline $\mathbf{4 0}$ & 498 & 393 & 287 \\
\hline $\mathbf{6 0}$ & $\geq 500$ & 402.8 & 302 \\
\hline $\mathbf{8 0}$ & $\geq 500$ & 410.2 & 312 \\
\hline $\mathbf{1 0 0}$ & $\geq 500$ & 416.2 & 312 \\
\hline $\mathbf{1 2 0}$ & $\geq 500$ & 421.1 & 303 \\
\hline $\mathbf{1 4 0}$ & $\geq 500$ & 424.8 & 319 \\
\hline $\mathbf{1 6 0}$ & $\geq 500$ & 428.8 & 322 \\
\hline $\mathbf{1 8 0}$ & $\geq 500$ & 430.7 & 327 \\
\hline $\mathbf{2 0 0}$ & $\geq 500$ & 433.9 & 325 \\
\hline
\end{tabular}




\section{Figures}

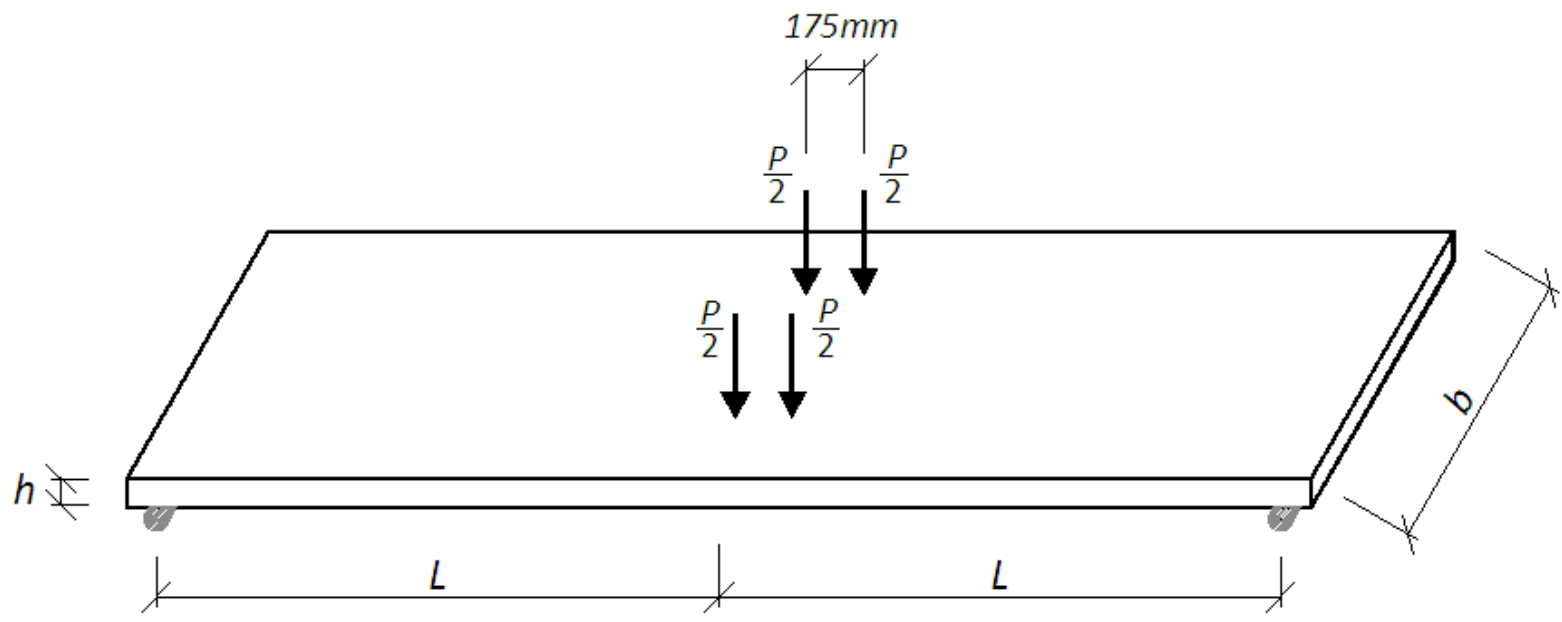

Figure $1 \quad$ General schematic of test-rig

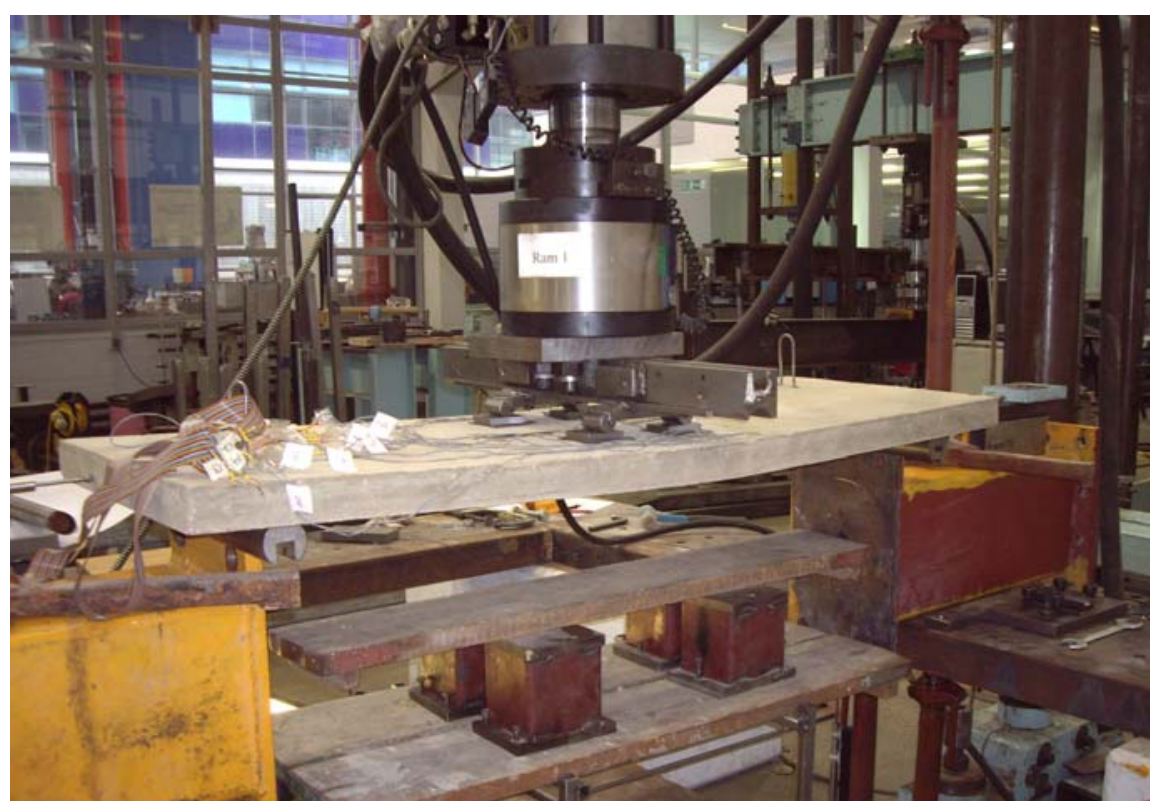

Figure $2 \quad$ View of test set up 


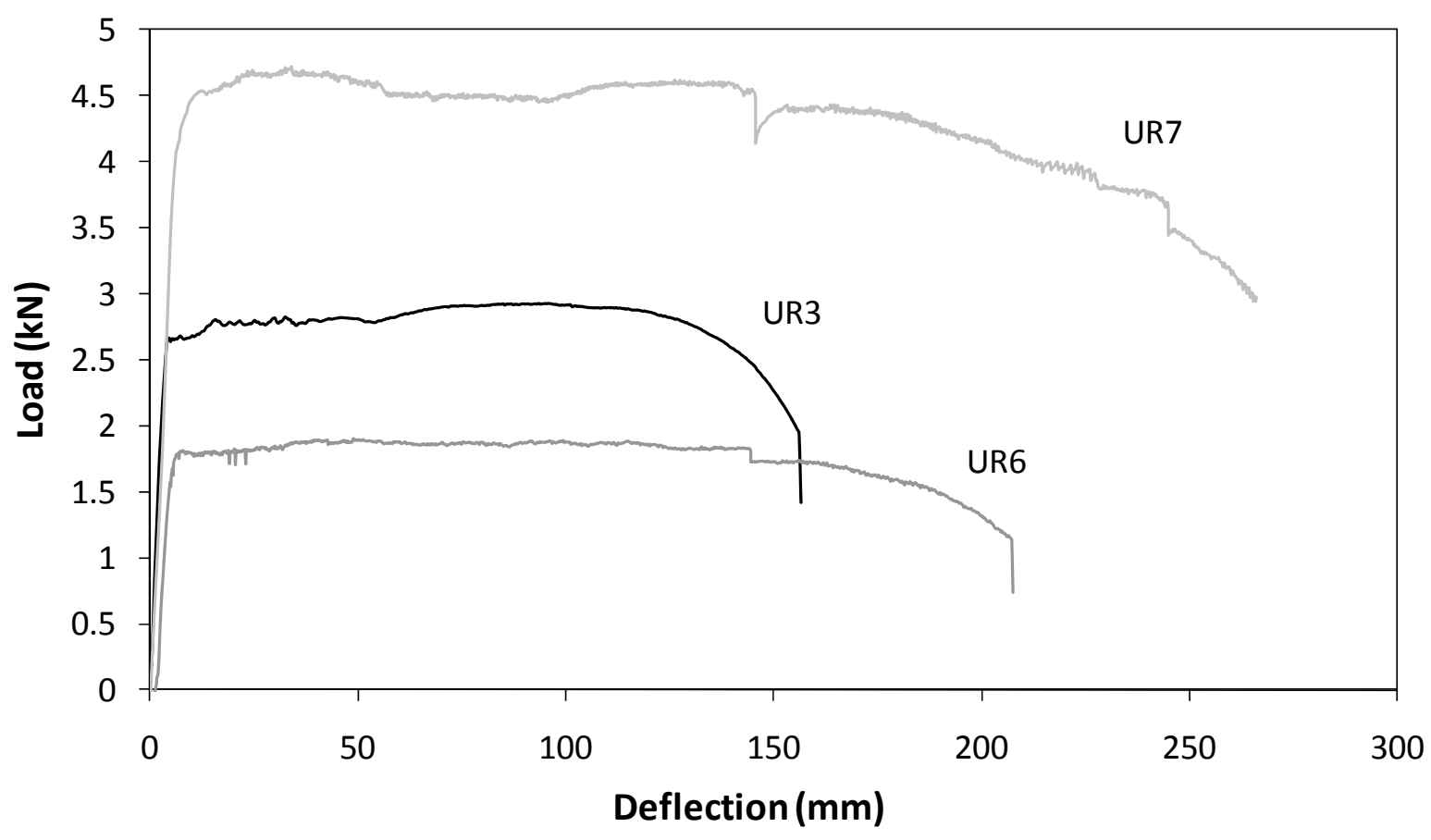

(a): P6

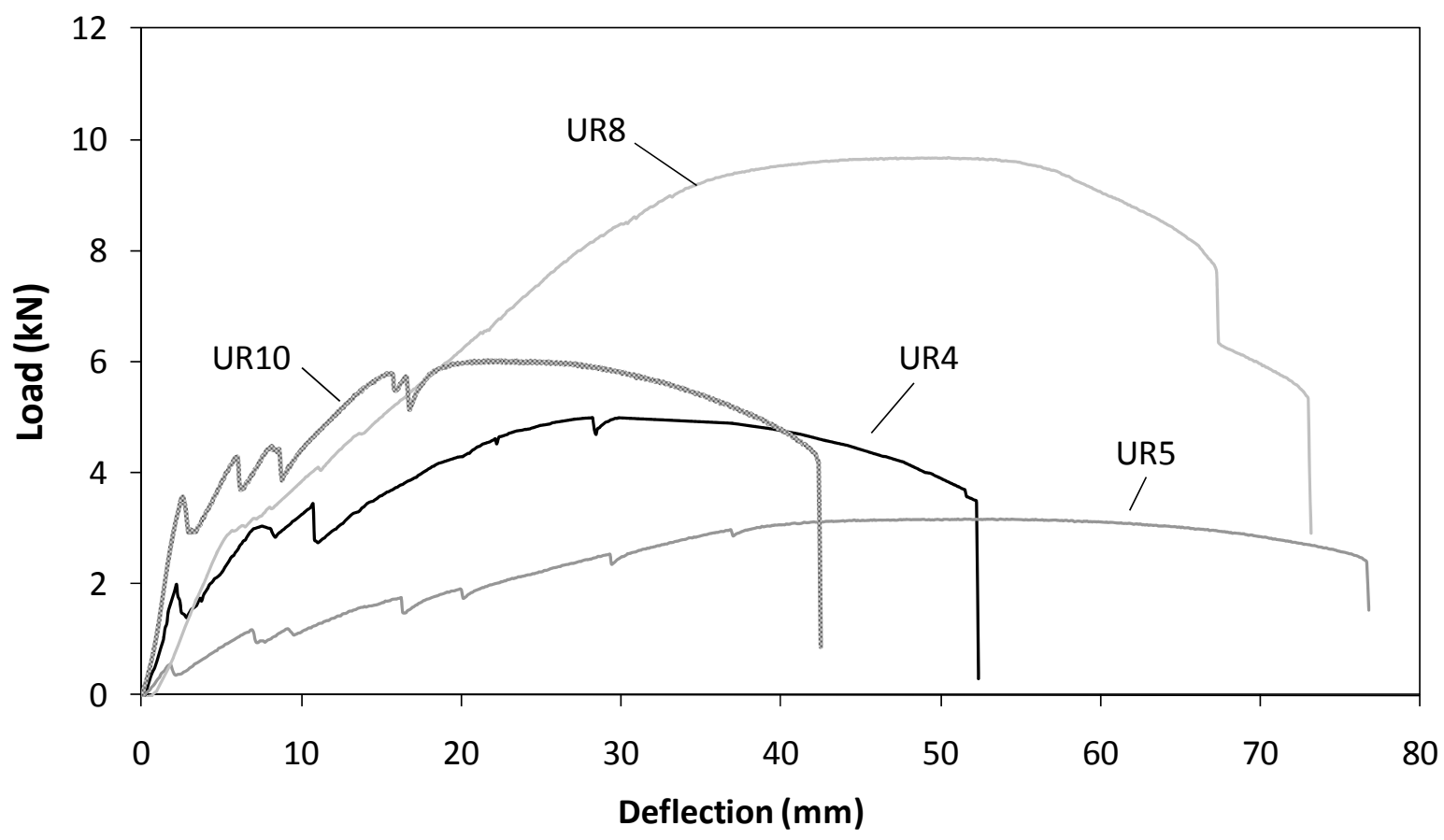

(b): D6 


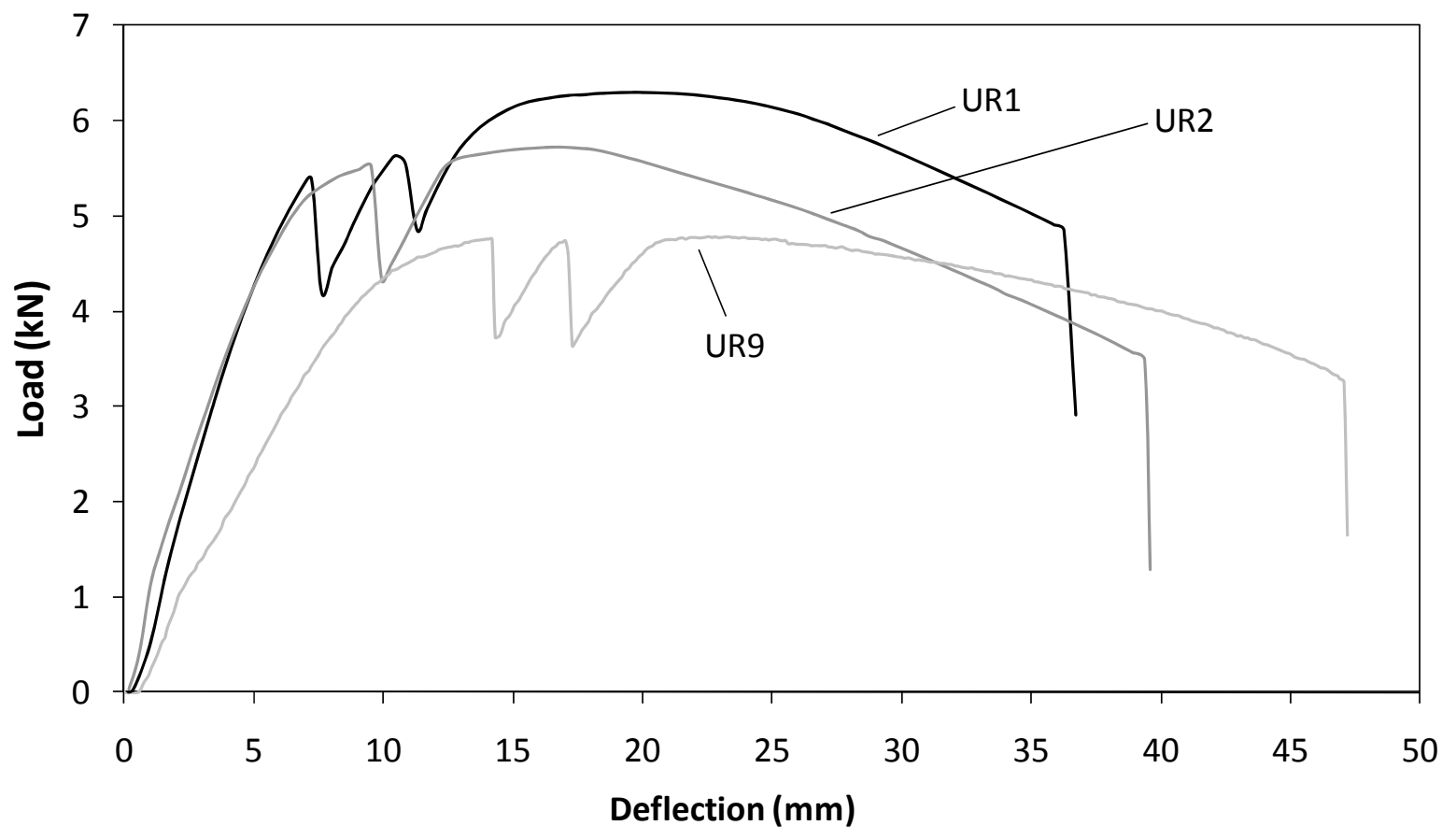

(c): M6

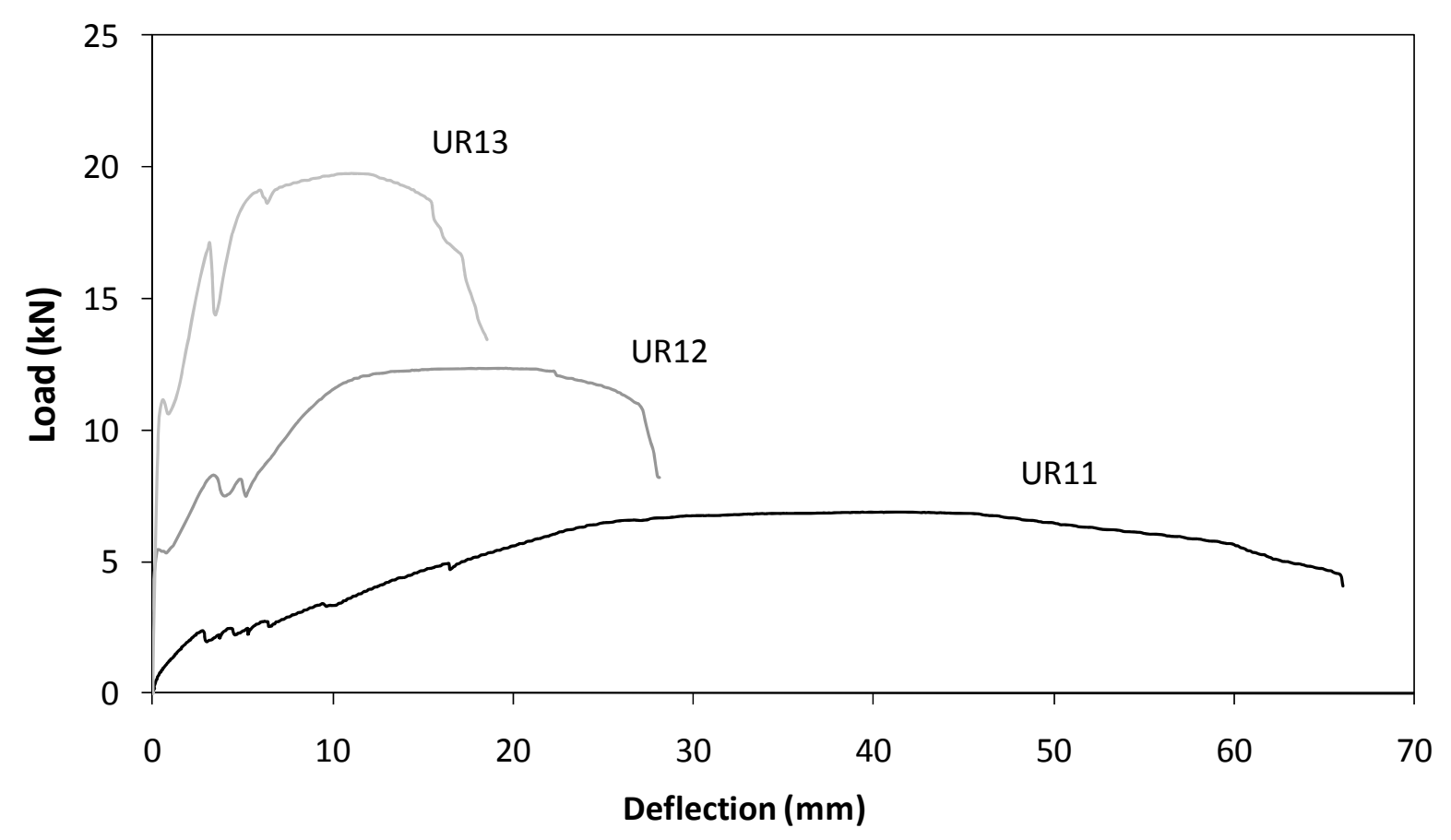

(d): D8

Figure 3 Experimental load-deflection response for member tests 


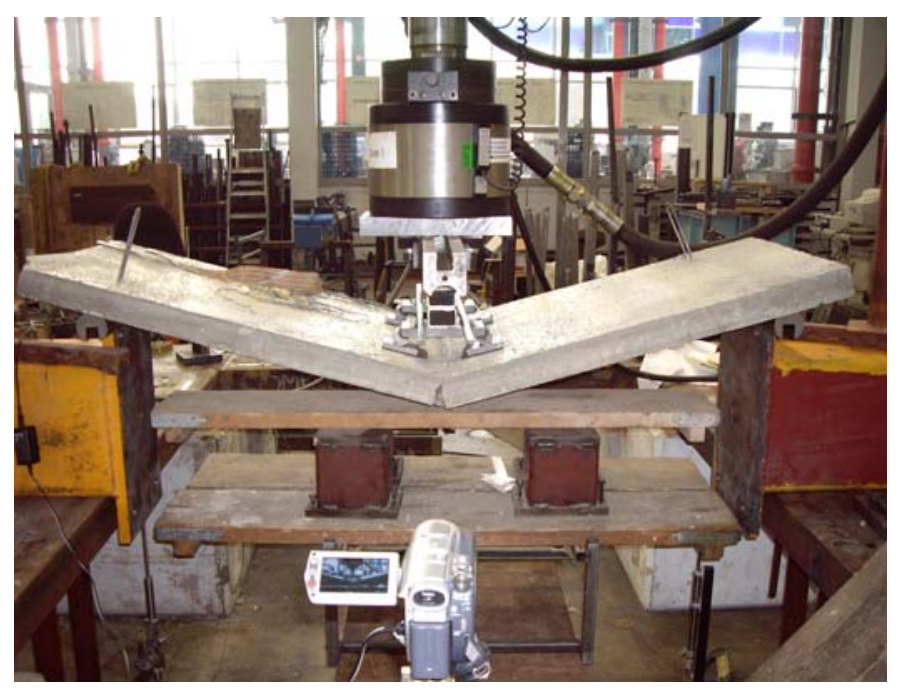

(a) Typical experimental response

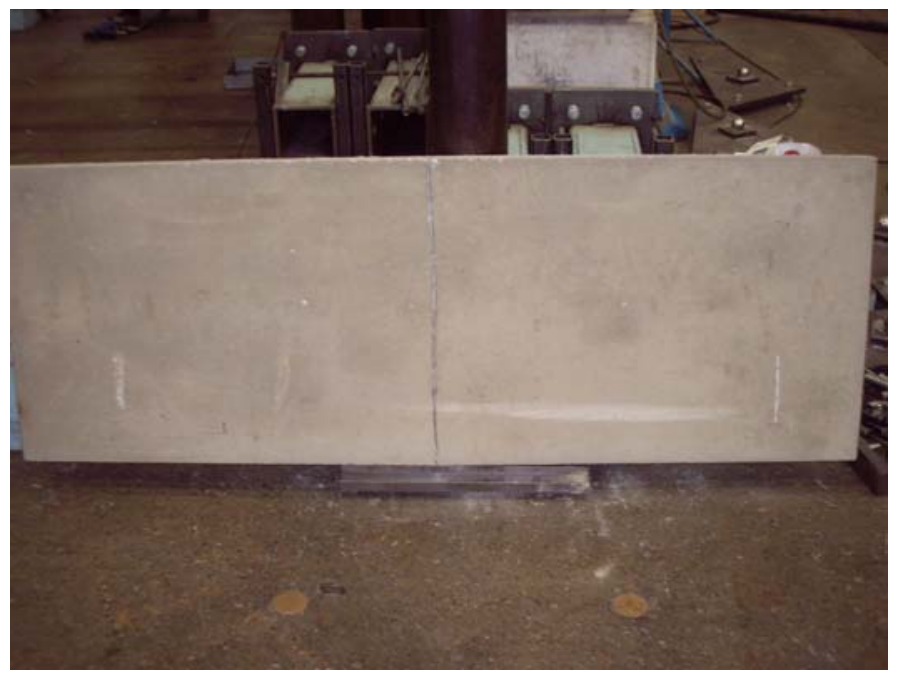

(b)Single crack in UR6

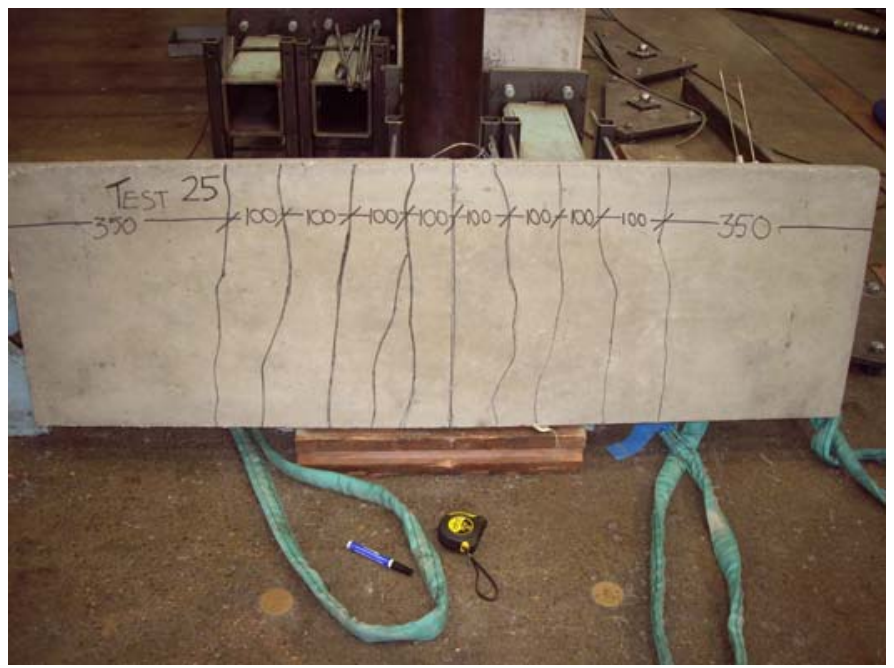

(c) Multiple cracks in UR8

Figure $4 \quad$ Experimental behaviour of simply supported strips 


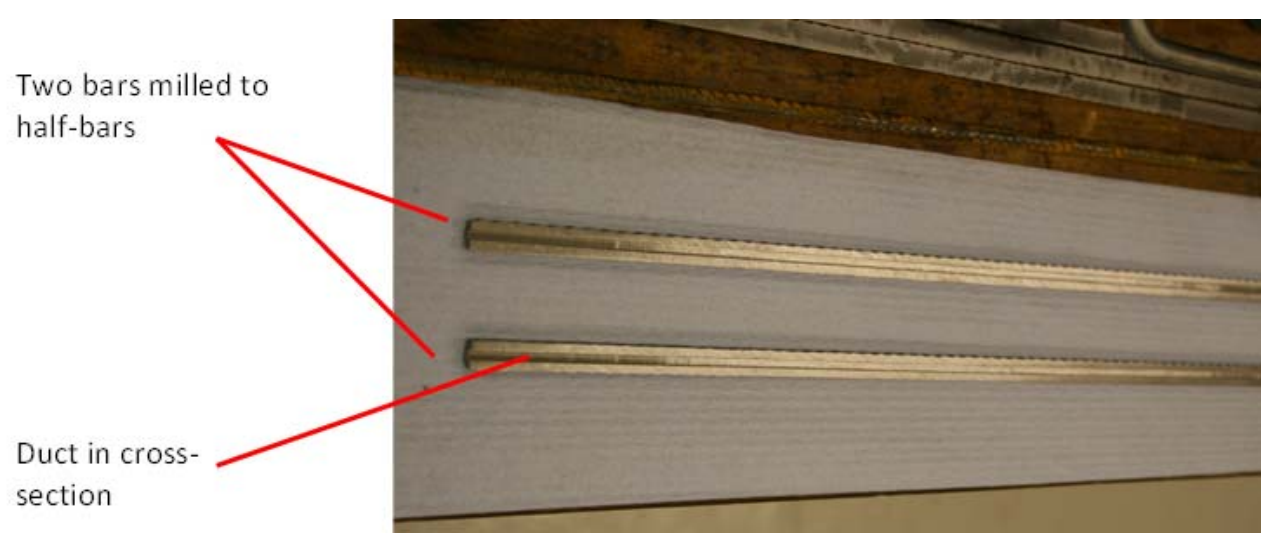

(a) Two half-bars showing the milled groove

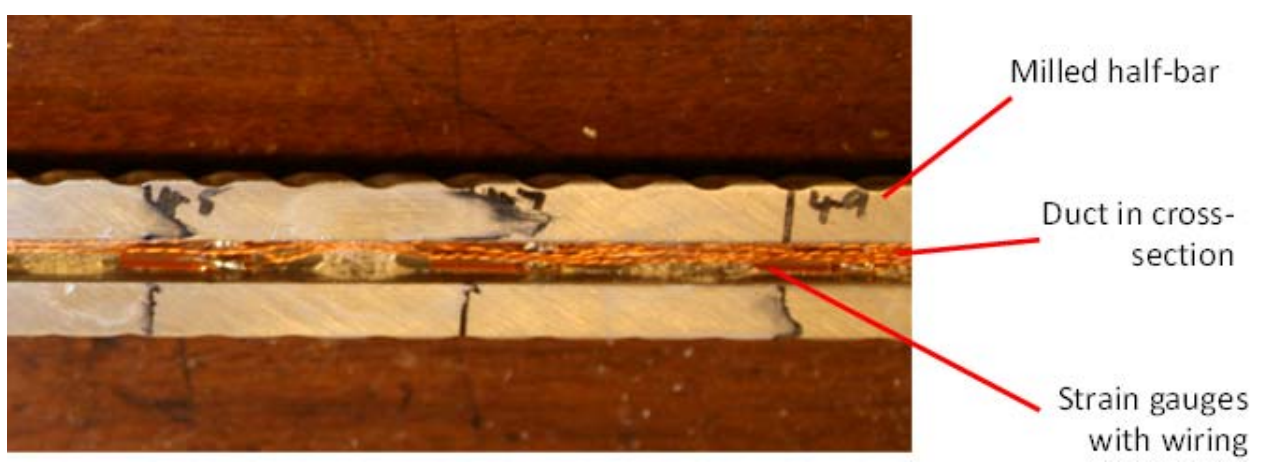

(b) Internal strain gauges in the reinforcing bar

Figure $5 \quad$ Views of the instrumented reinforcement tests

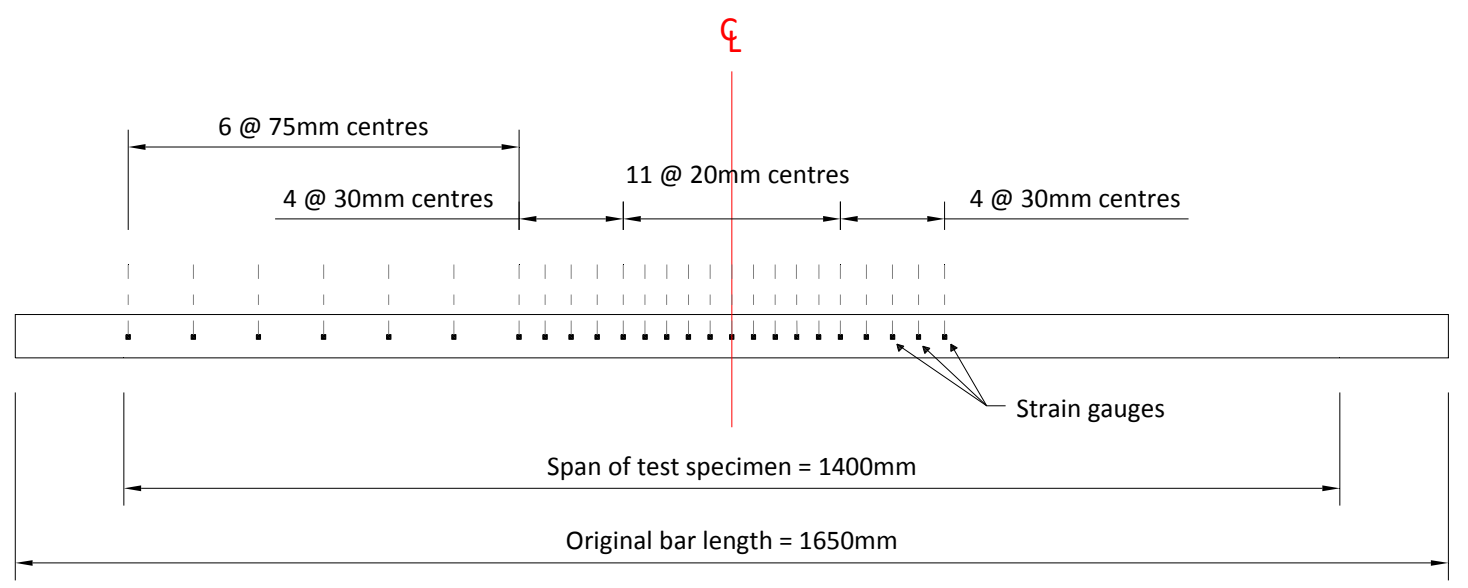

Figure $6 \quad$ Layout of strain gauges 


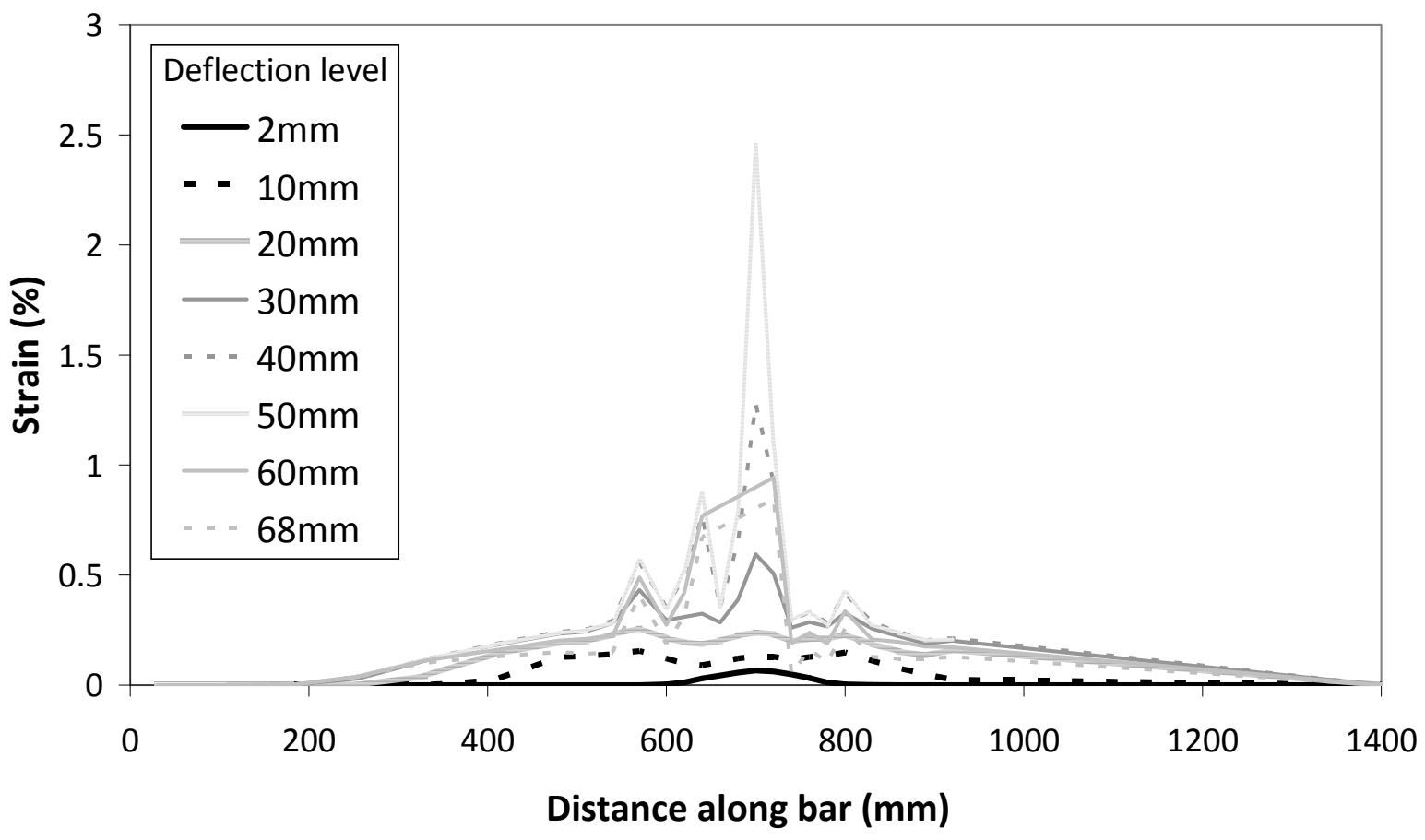

(a) Strain gauge data

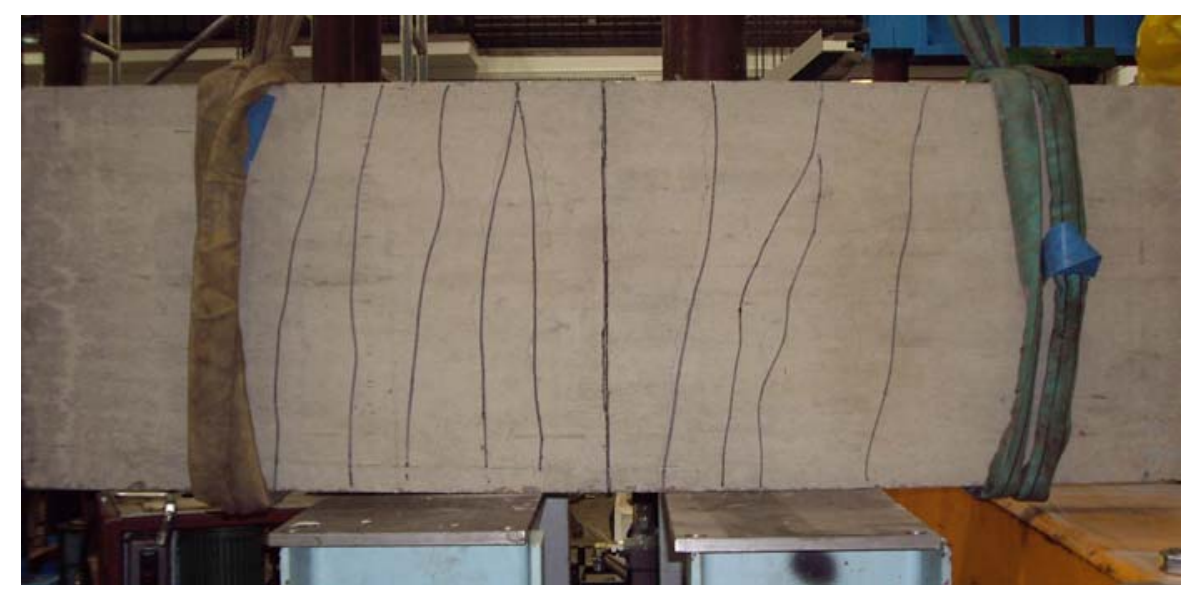

(b) Crack pattern

Figure $7 \quad$ Results from Test UR11 


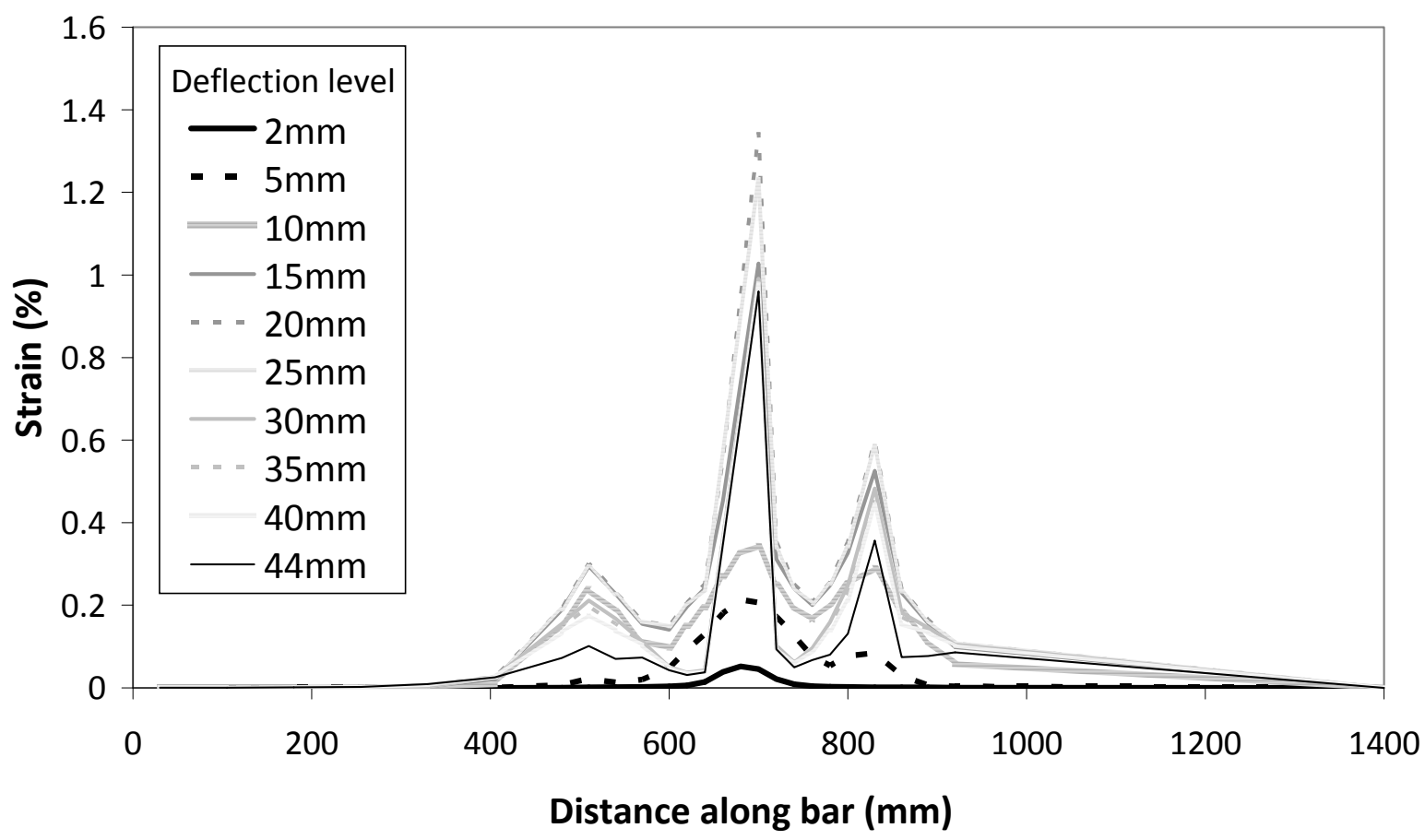

(a) Strain gauge data

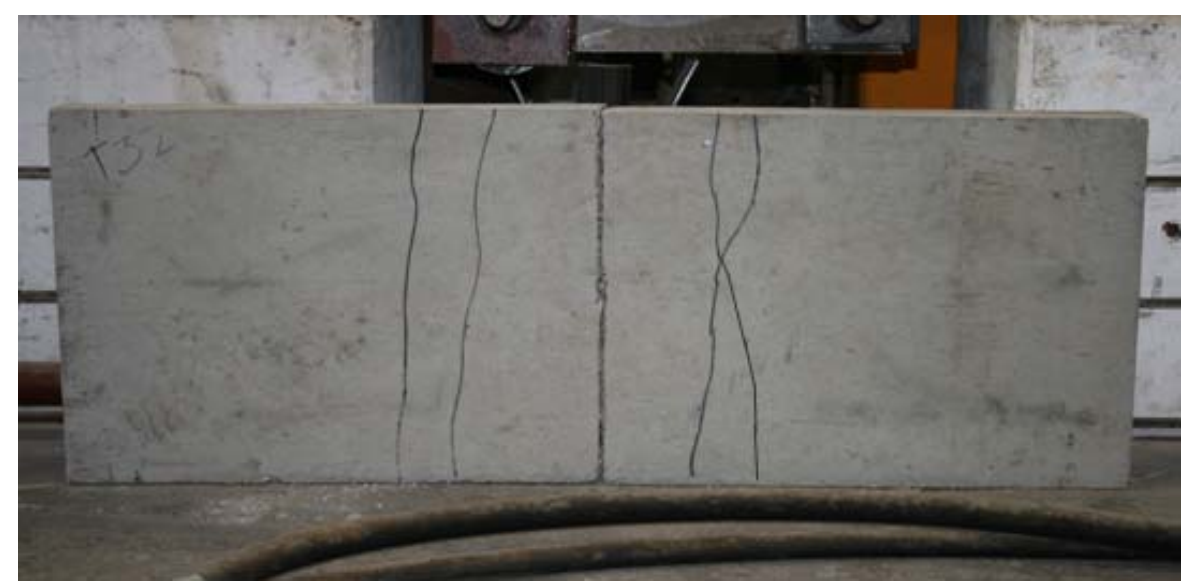

(b) Crack pattern

Figure $8 \quad$ Results from Test UR12 


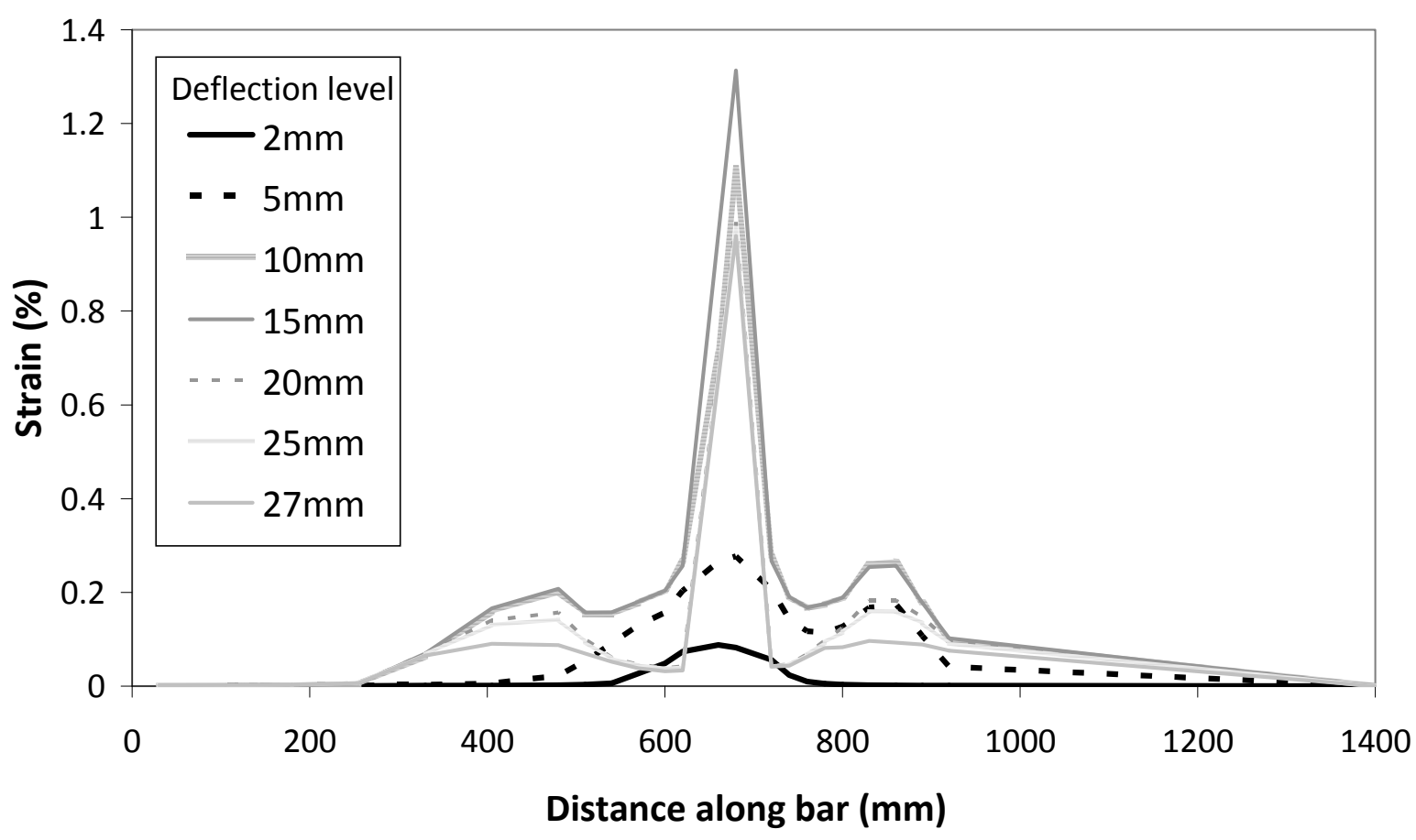

(a) Strain gauge data

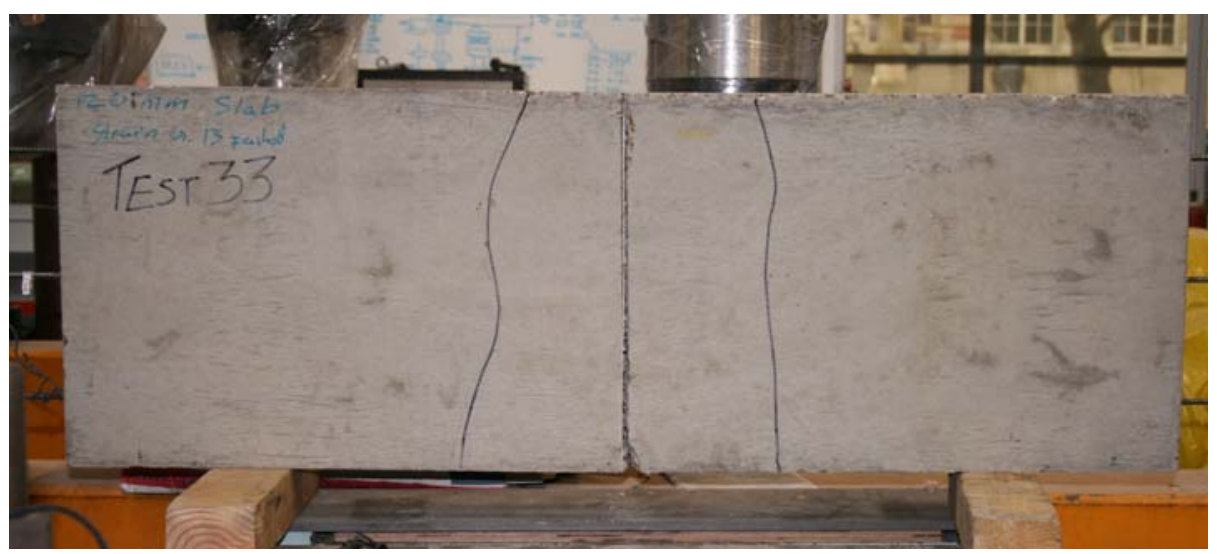

(b) Crack pattern

Figure 9 Results from Test UR13 


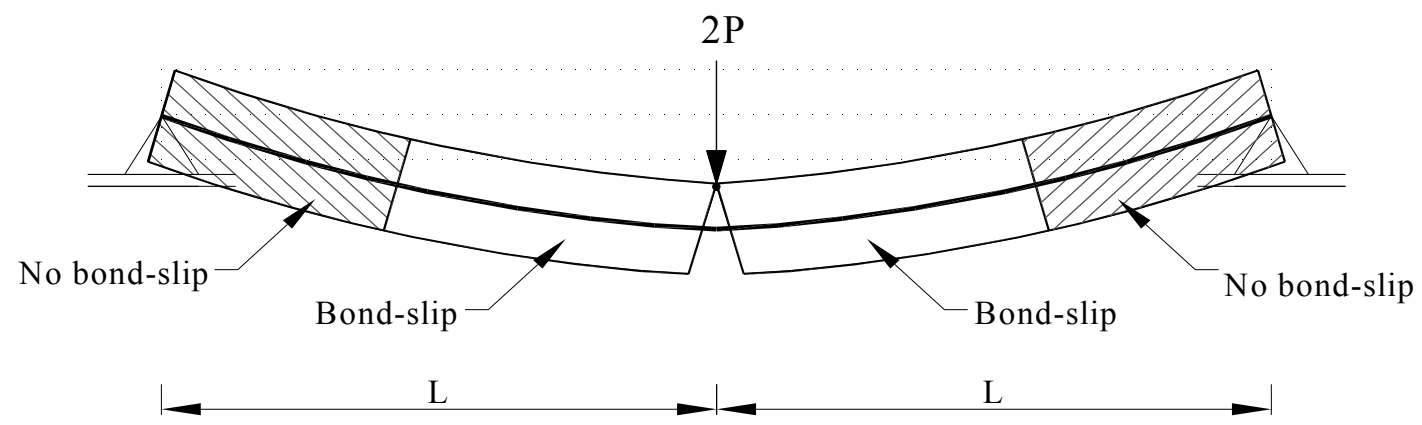

Figure 10 Layout of lightly reinforced member indicating bond-slip regions

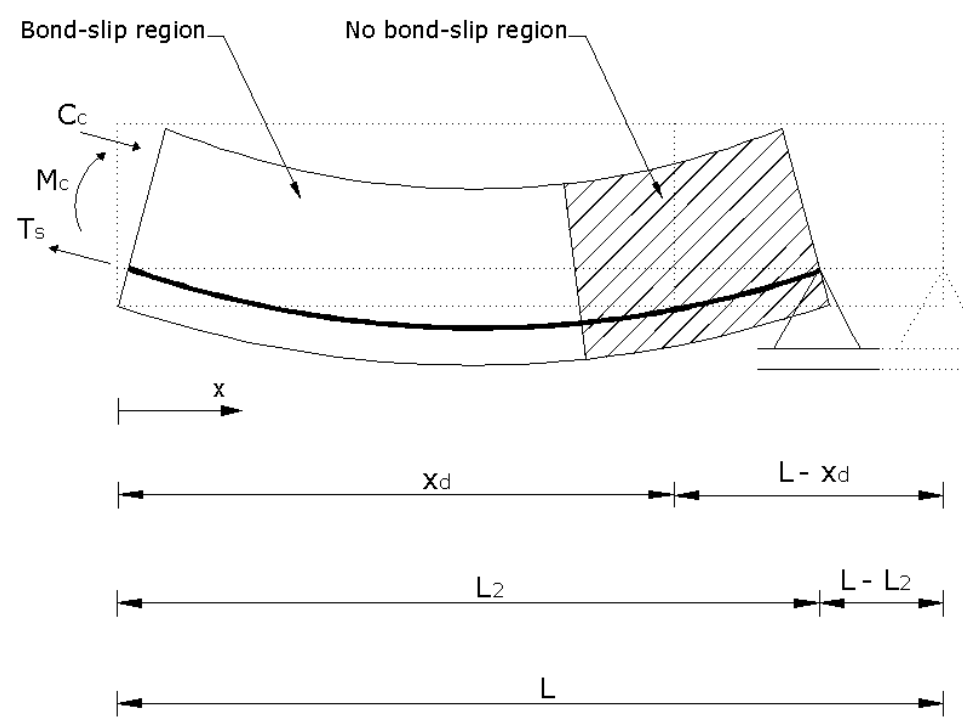

Figure $11 \quad$ Partial member model

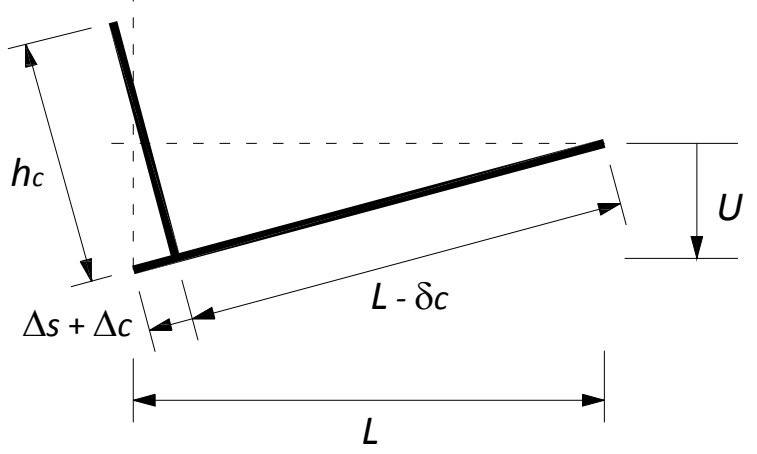

Figure 12 Compatibility diagram 


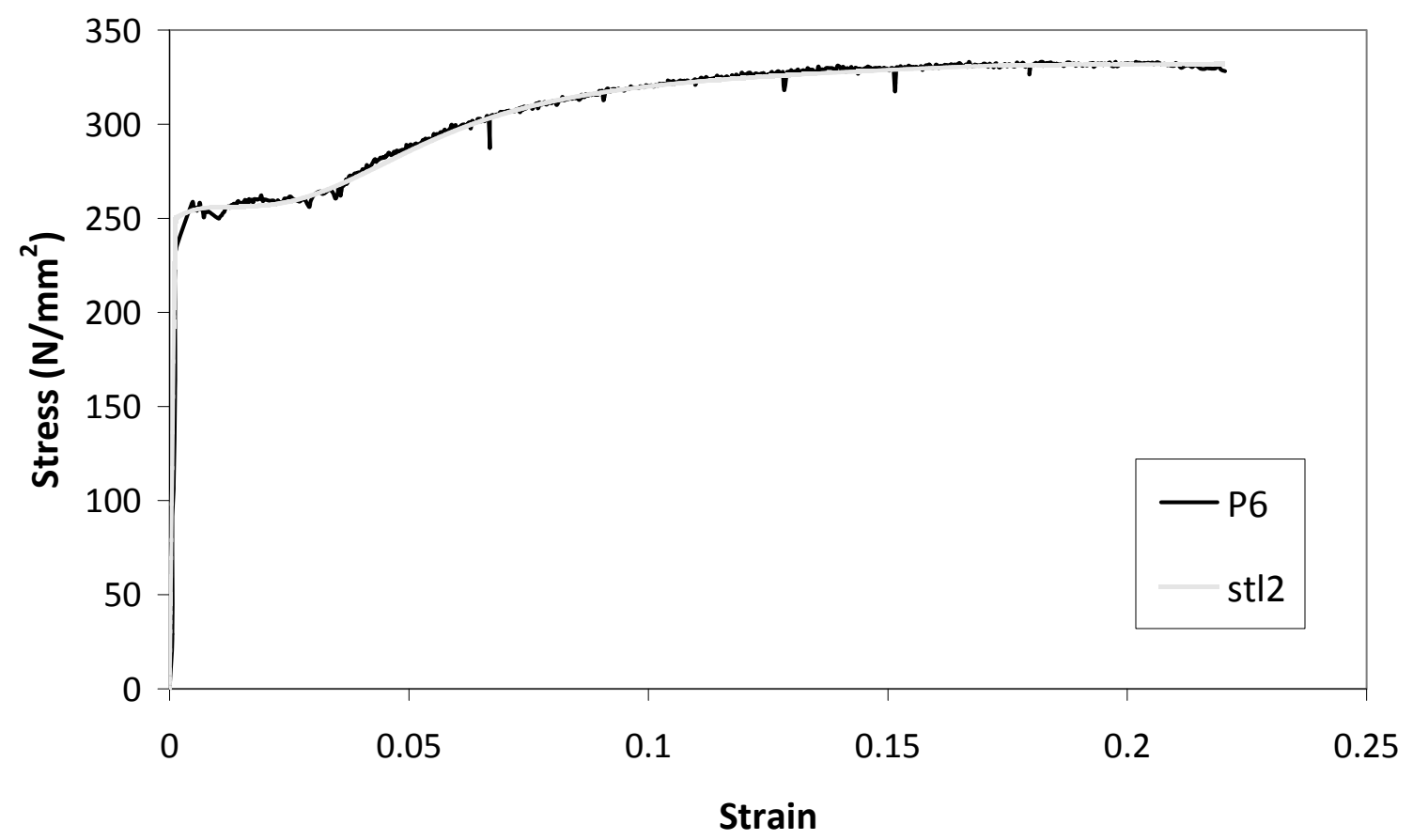

Figure 13 ADAPTIC steel material representation

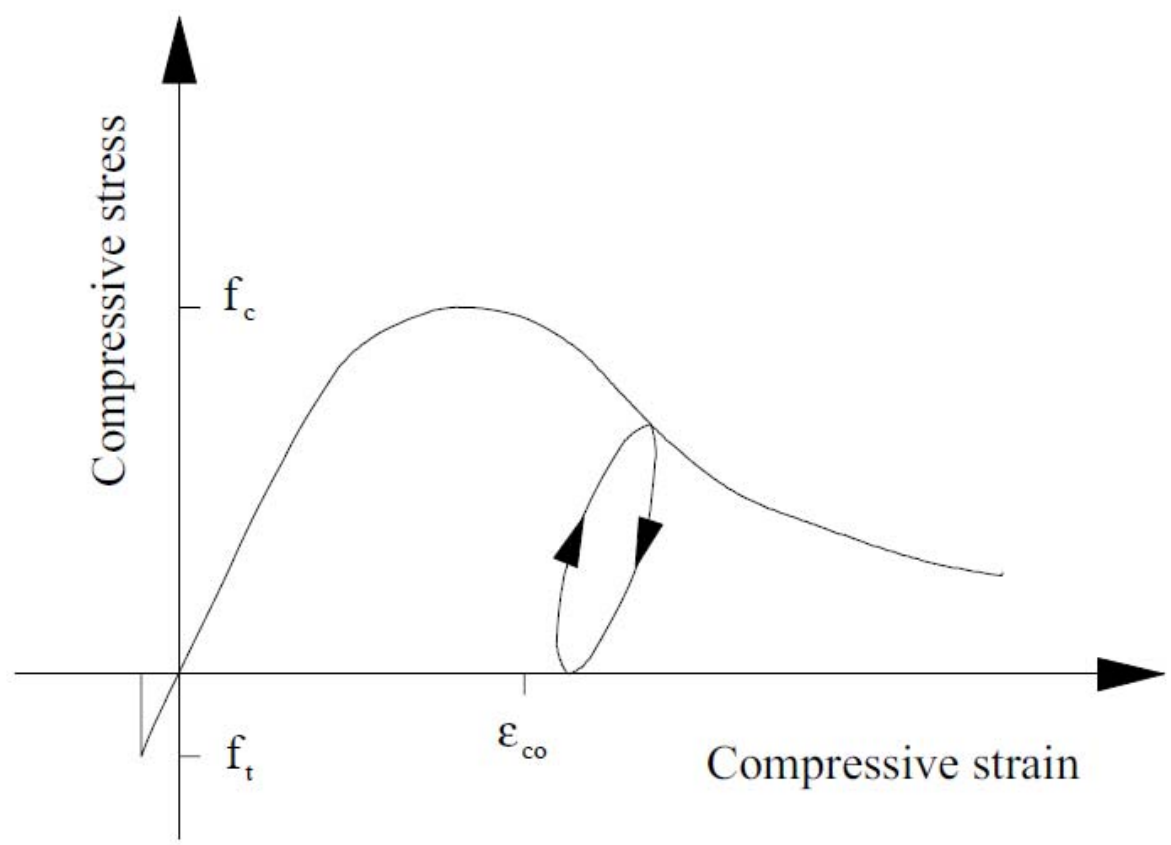

Figure 14 ADAPTIC con2 concrete material model [17] 


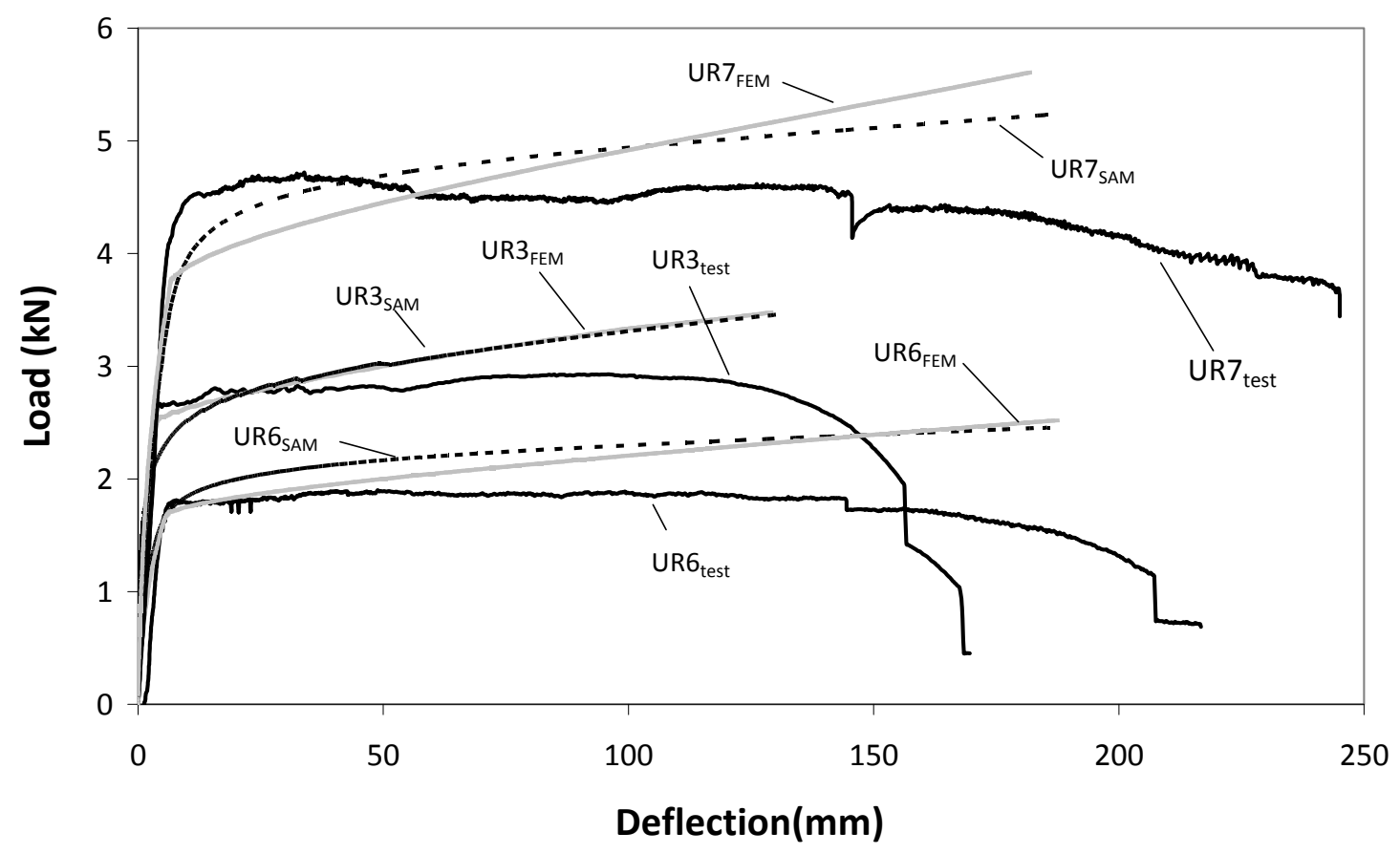

(a) P6

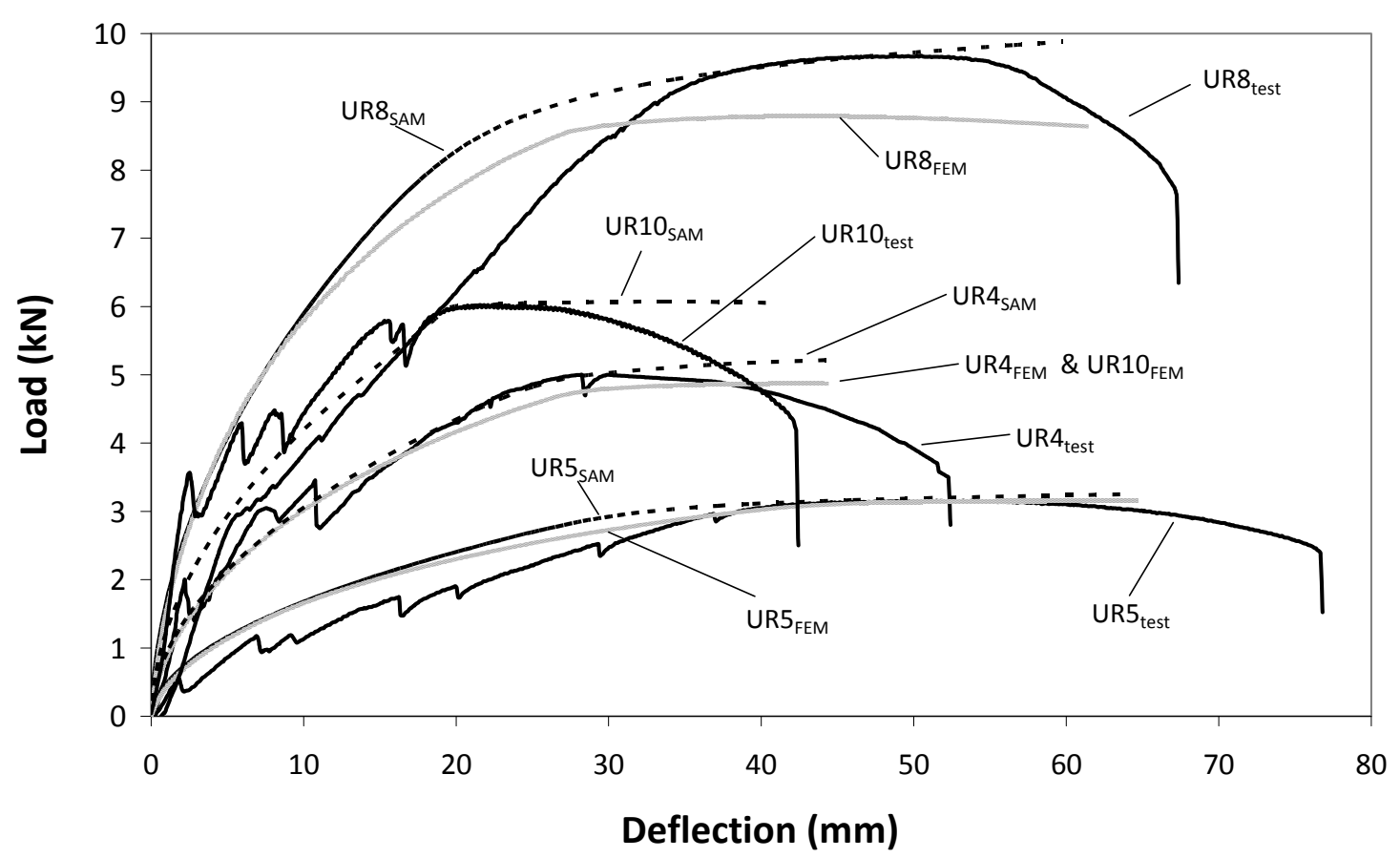

(b) D6 


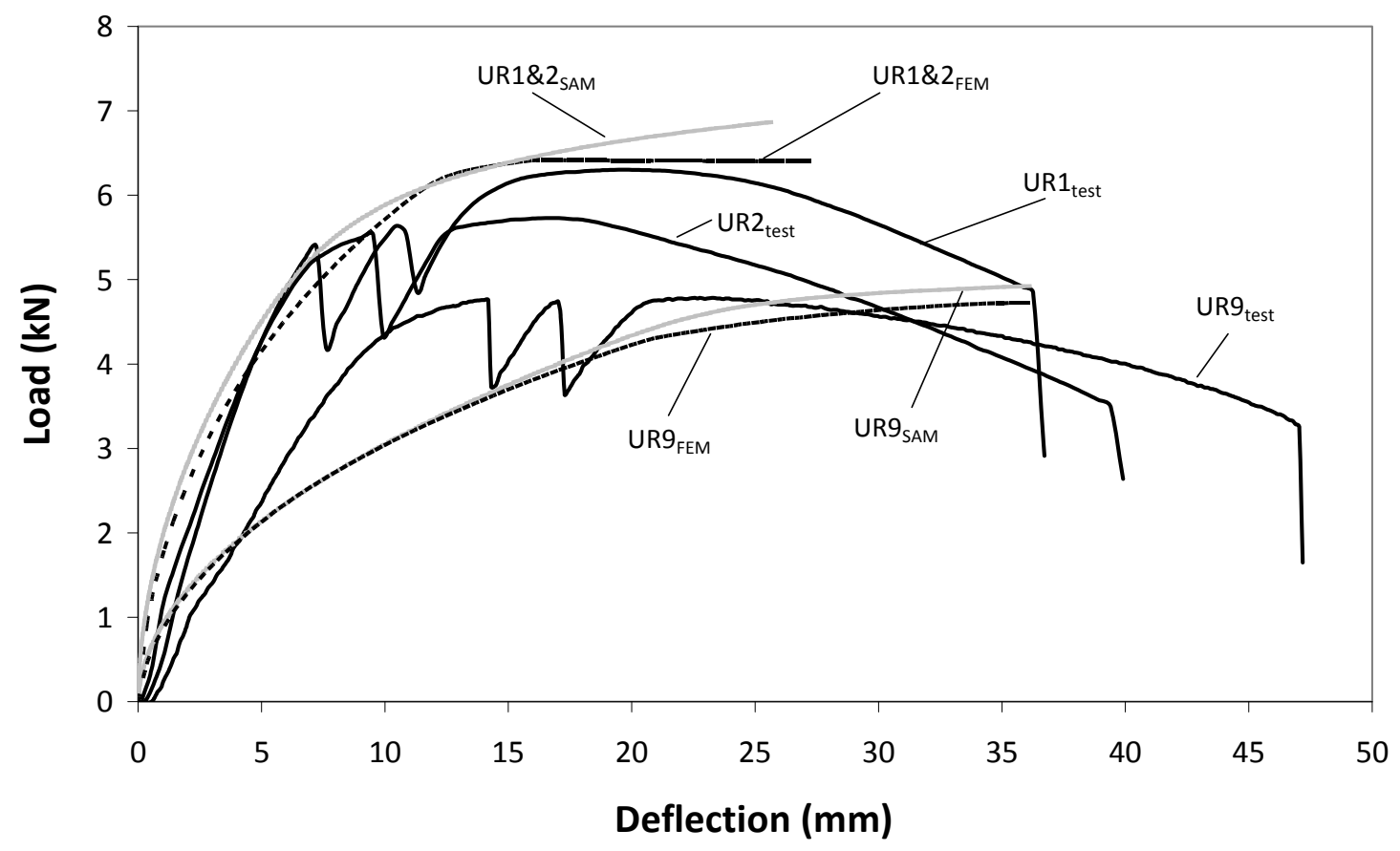

(c) M6

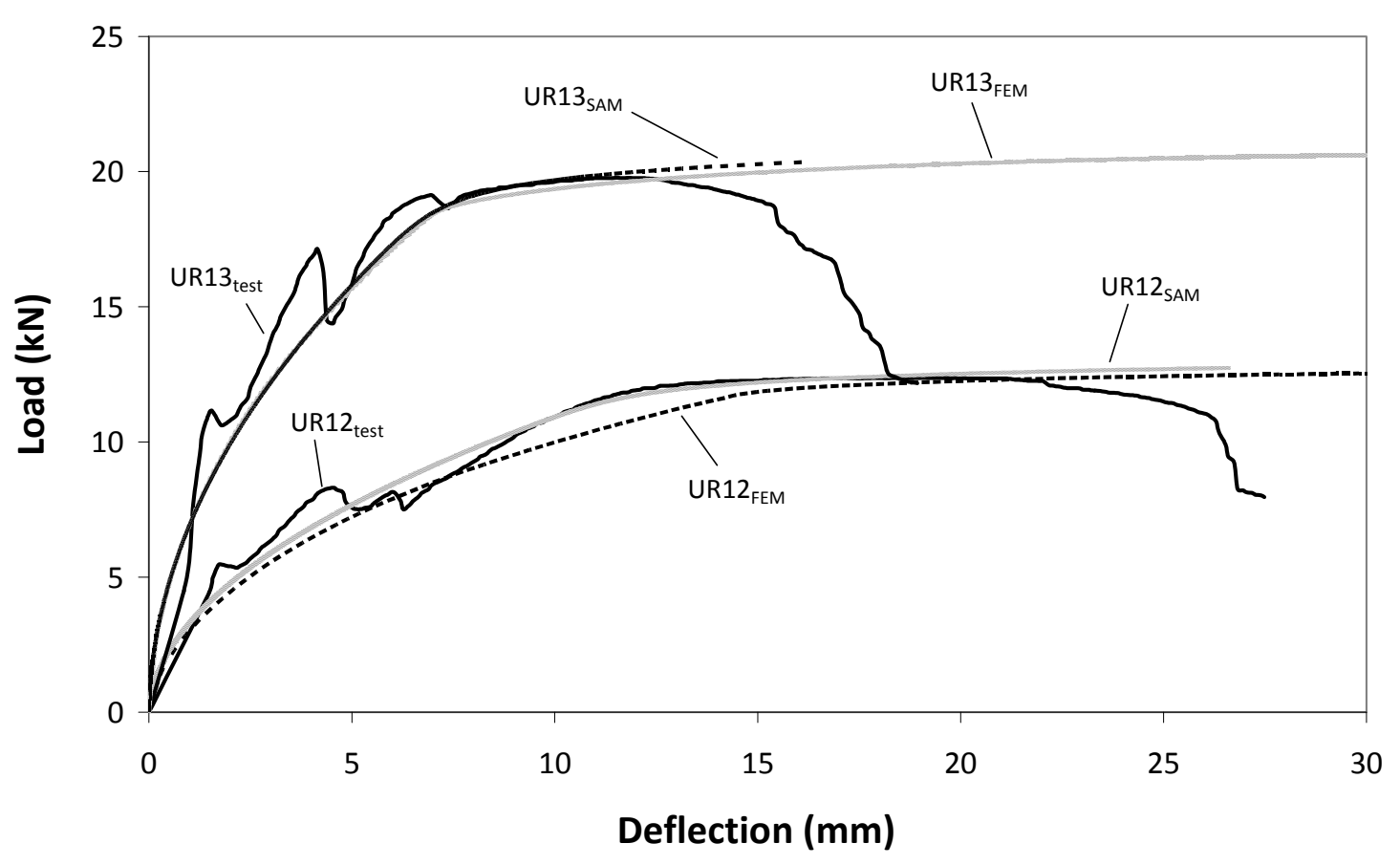

(d) D8

Figure 15 Comparison of load-deflection response for strip elements 


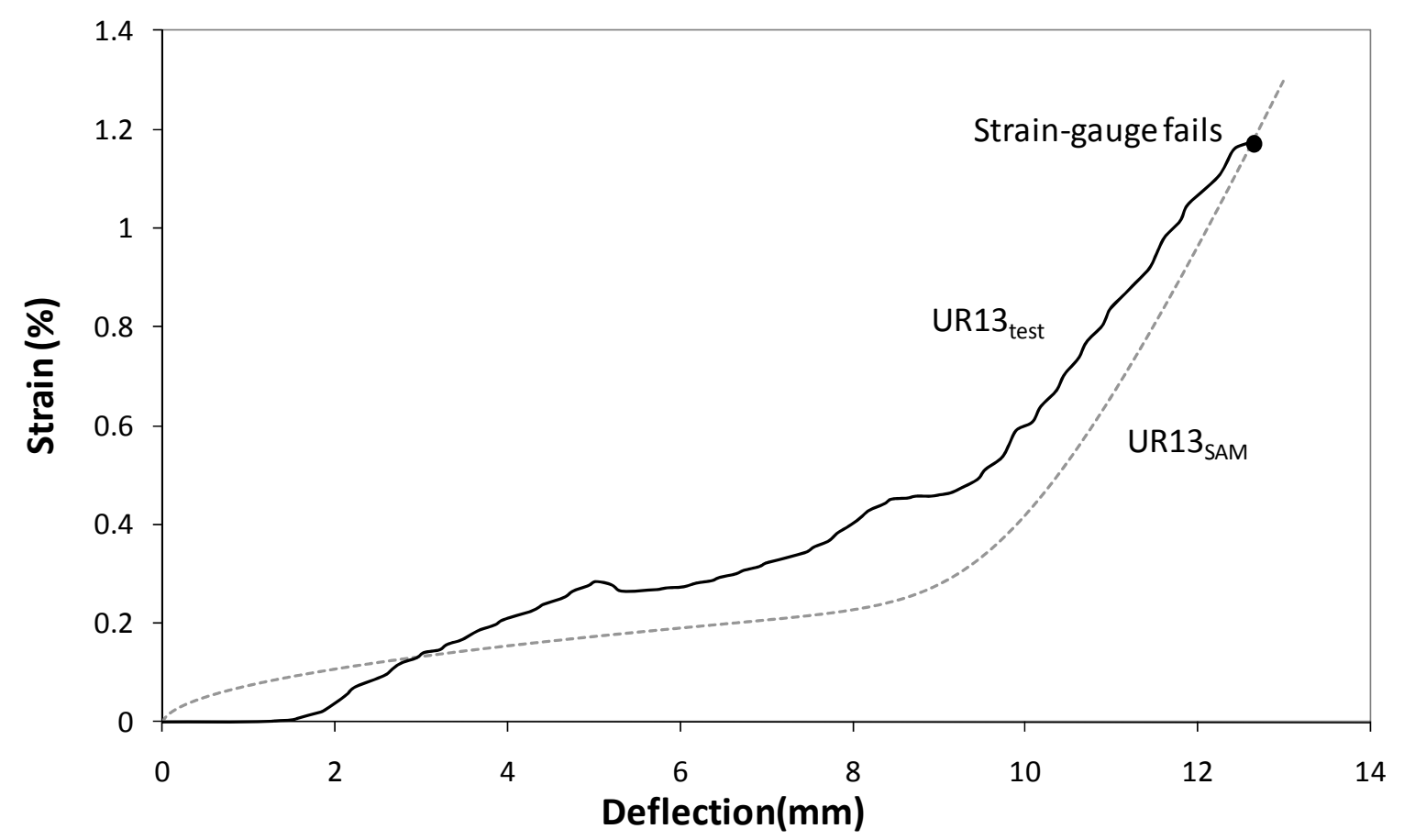

Figure 16 Comparison of strain-displacement response

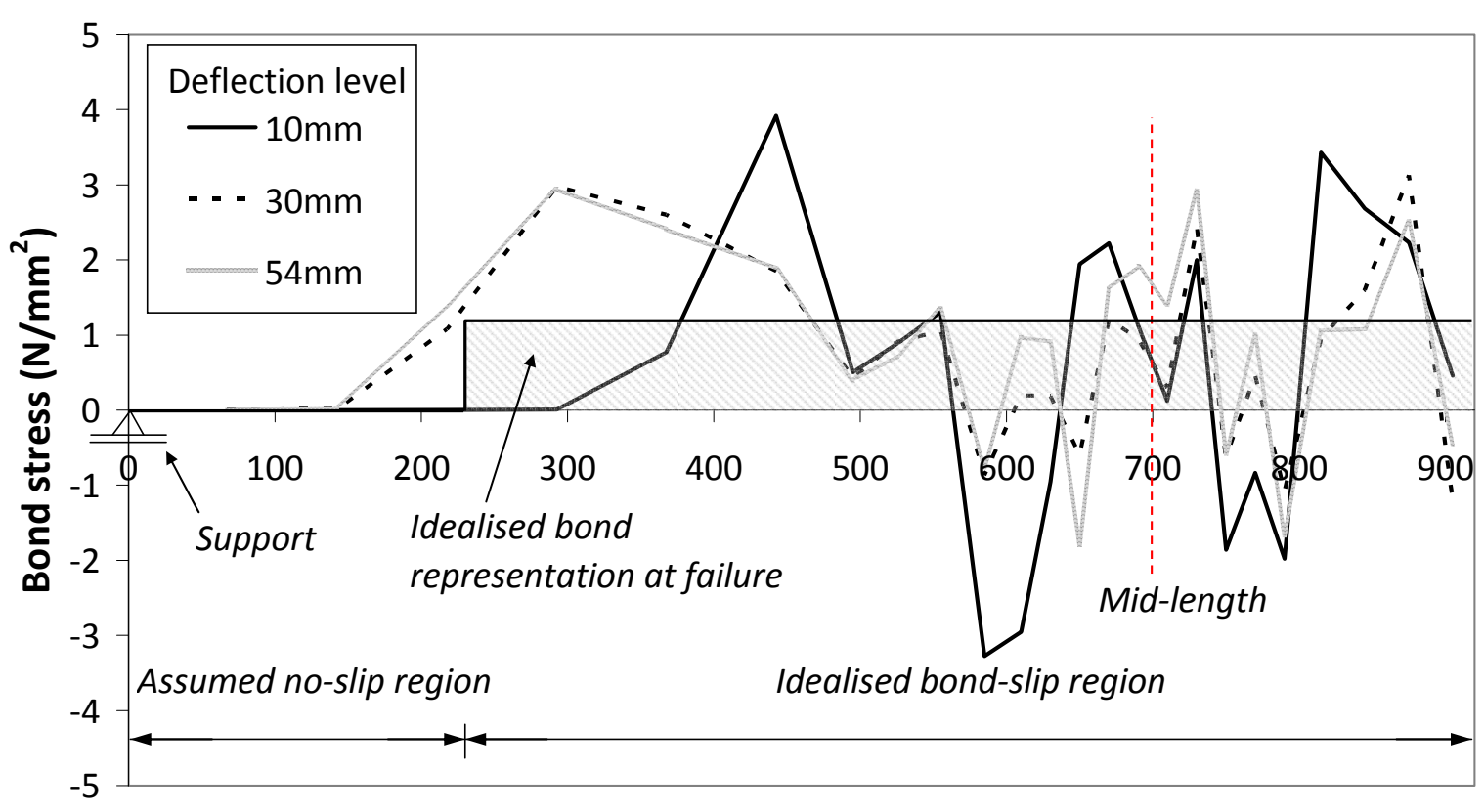

Distance along bar ( $\mathrm{mm})$

(a) UR11 


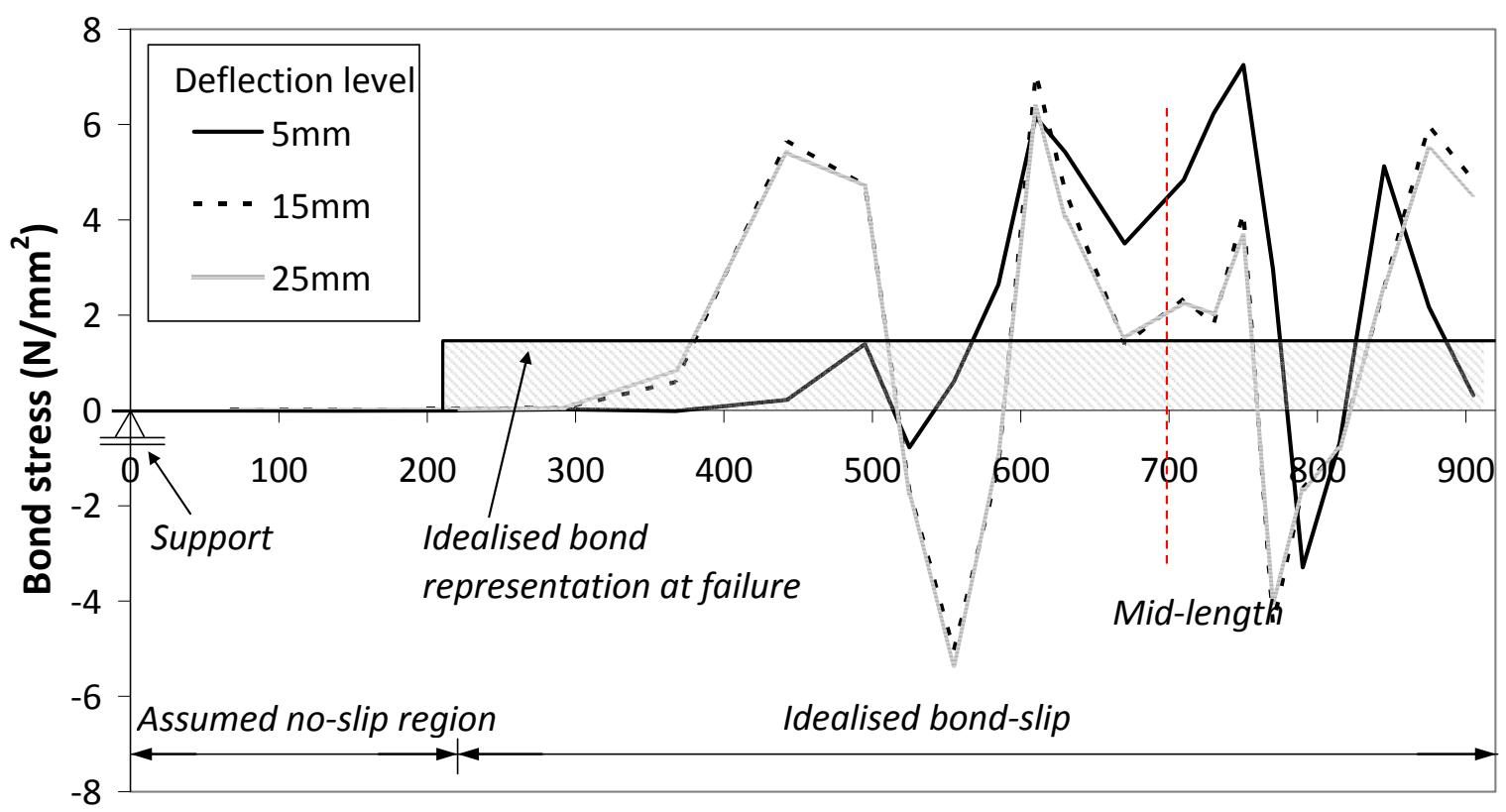

Distance along bar ( $\mathrm{mm})$

(b) UR12

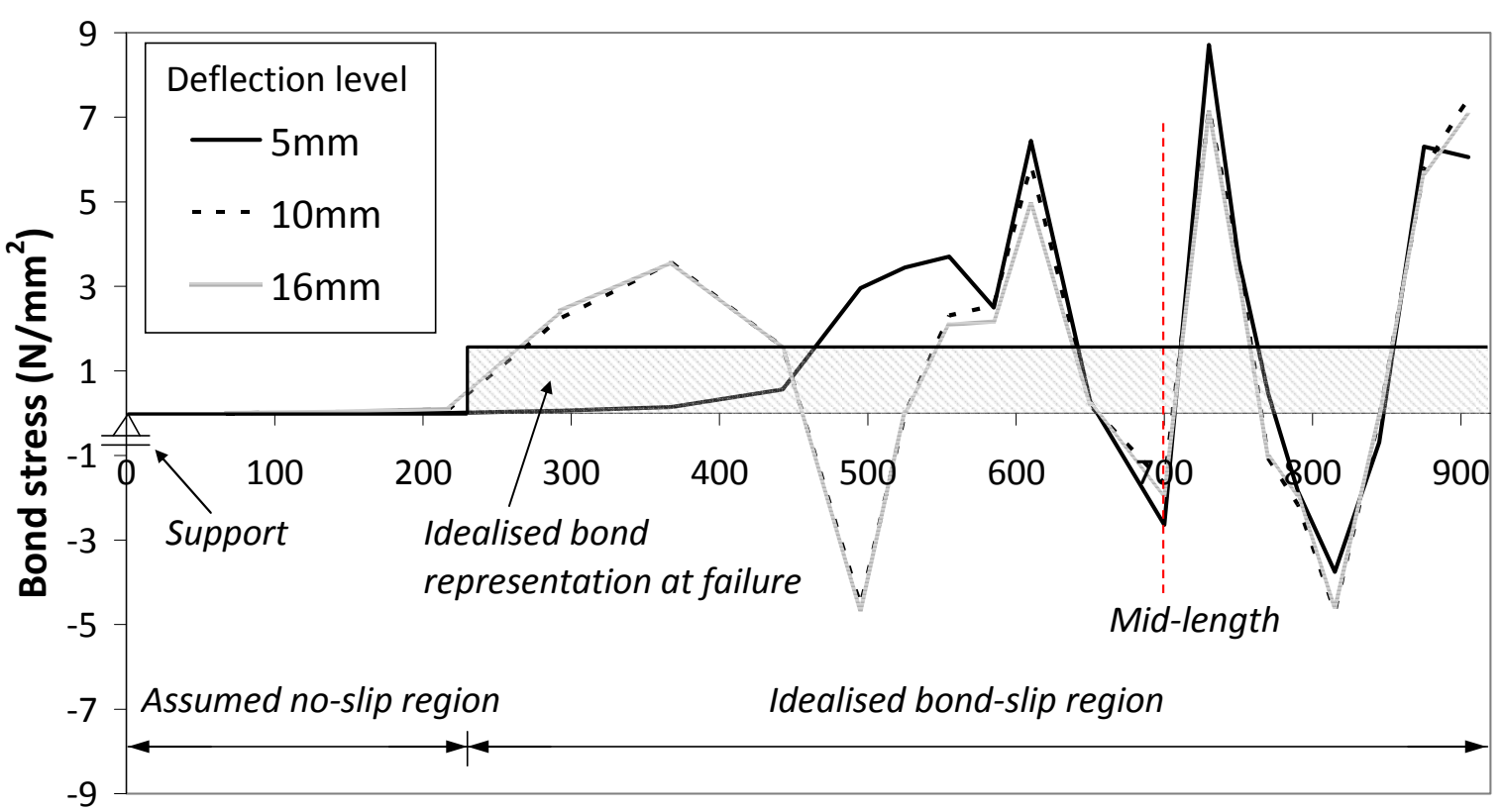

Distance along bar $(\mathrm{mm})$

(c) UR13

Figure 17 Bond distribution along the length at various levels of vertical deflection 


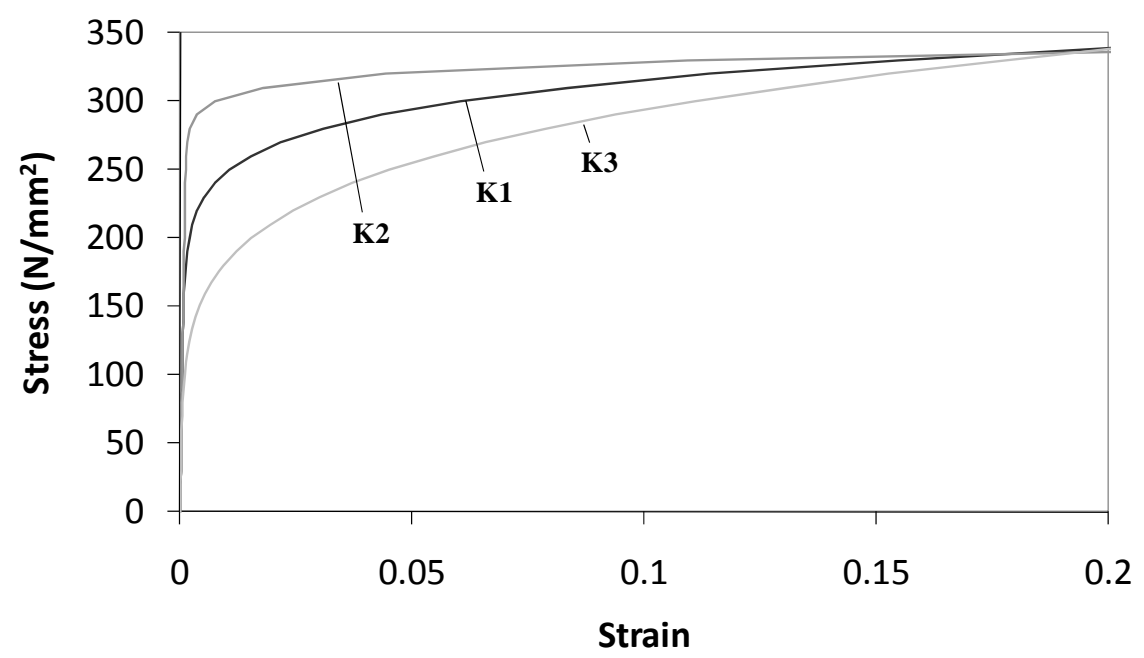

(a) Various steel constitutive relationships

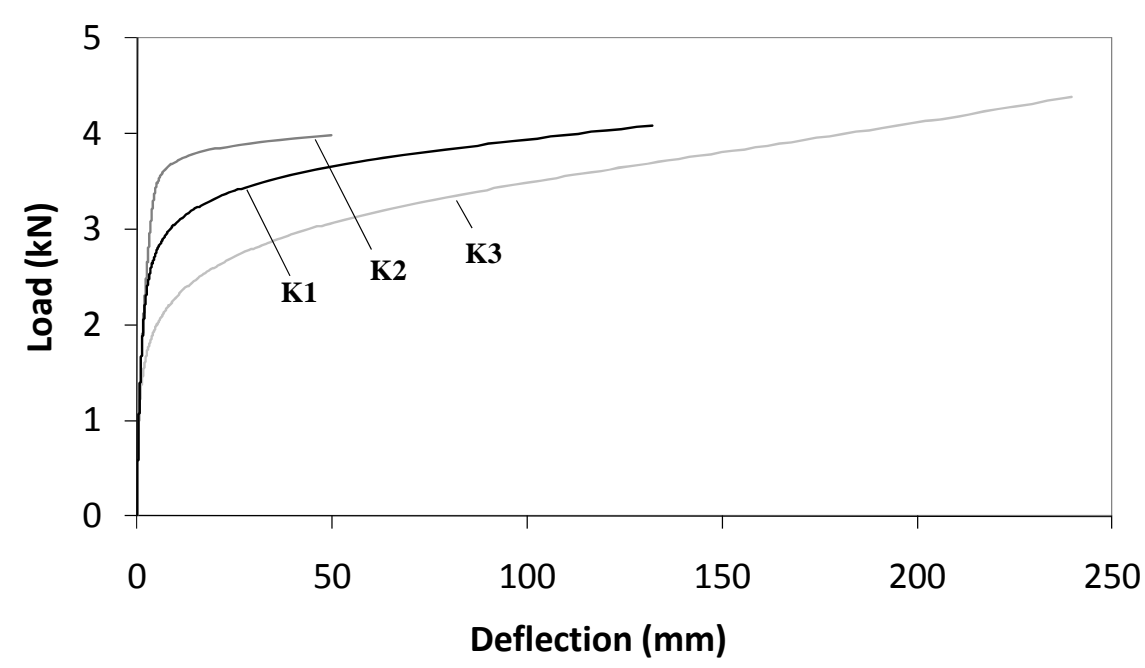

(b) Load-deflection response

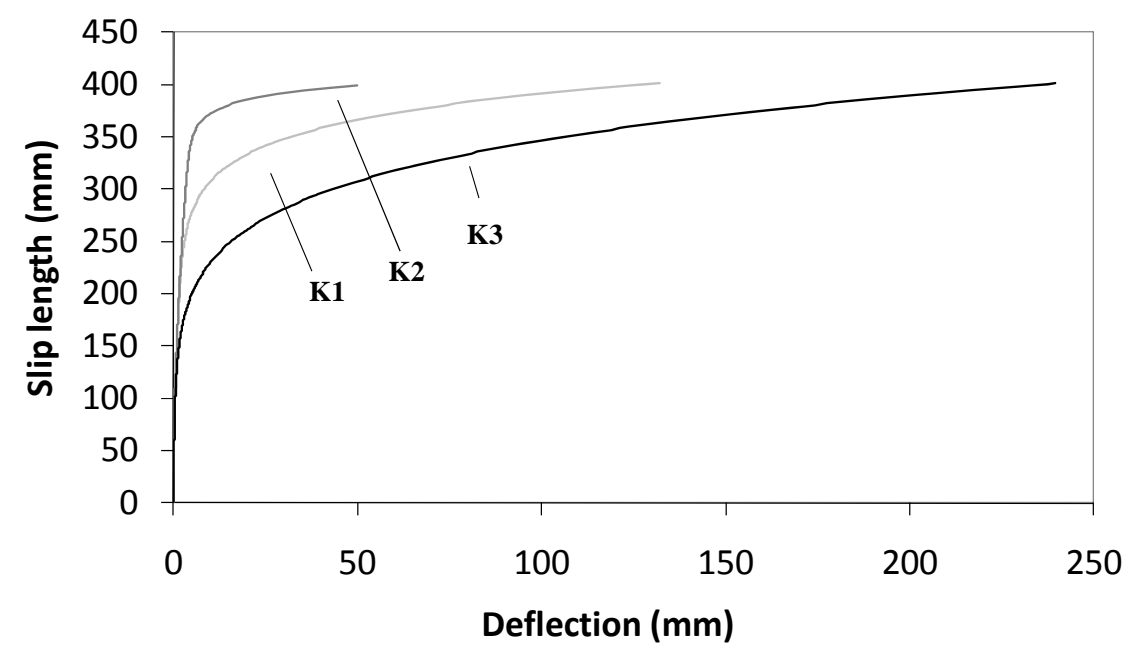

(c) Slip length-deflection response

Figure 18 Effect of various steel constitutive relationships on behaviour 


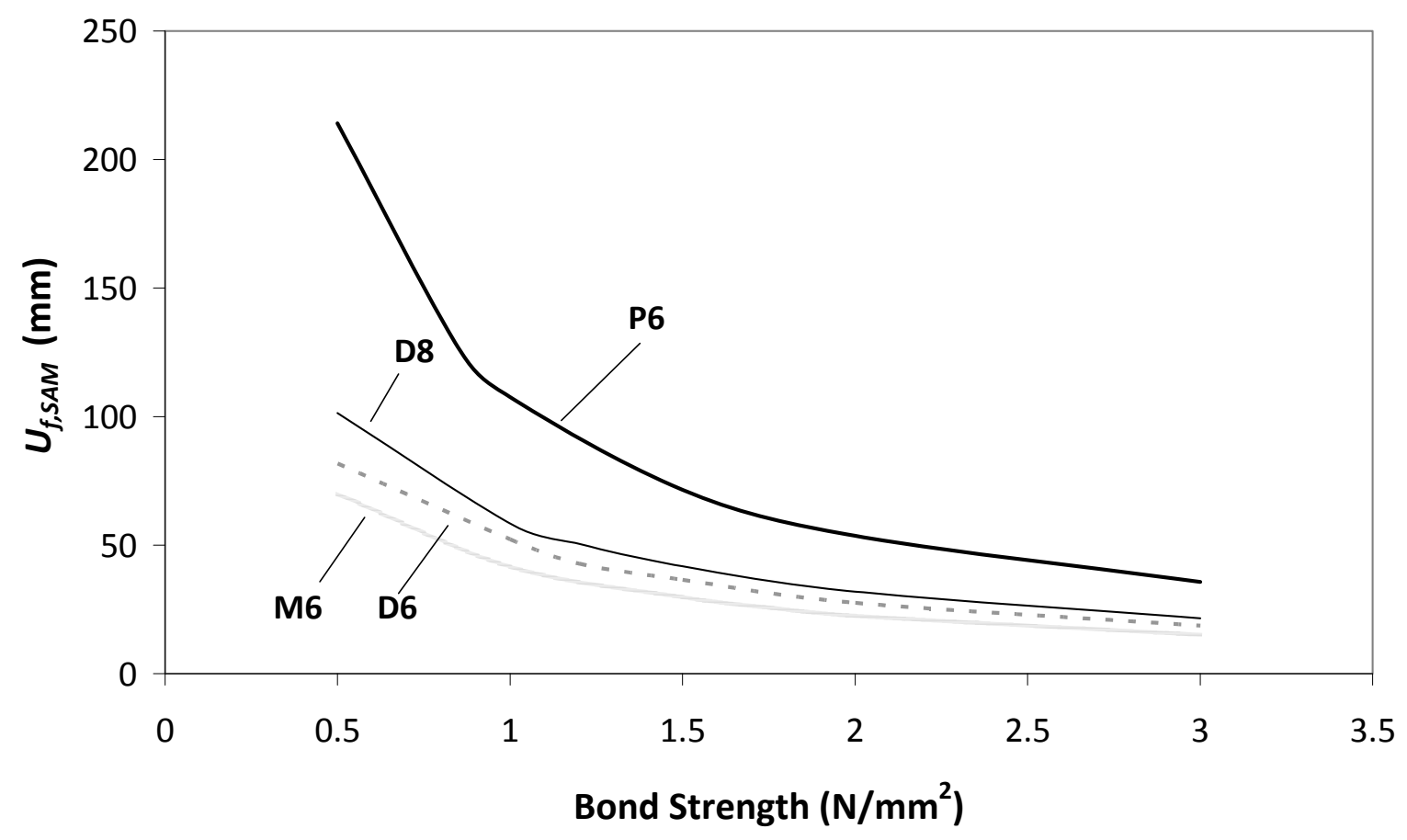

Figure 19 Effect of bond strength on failure displacement for different bar types

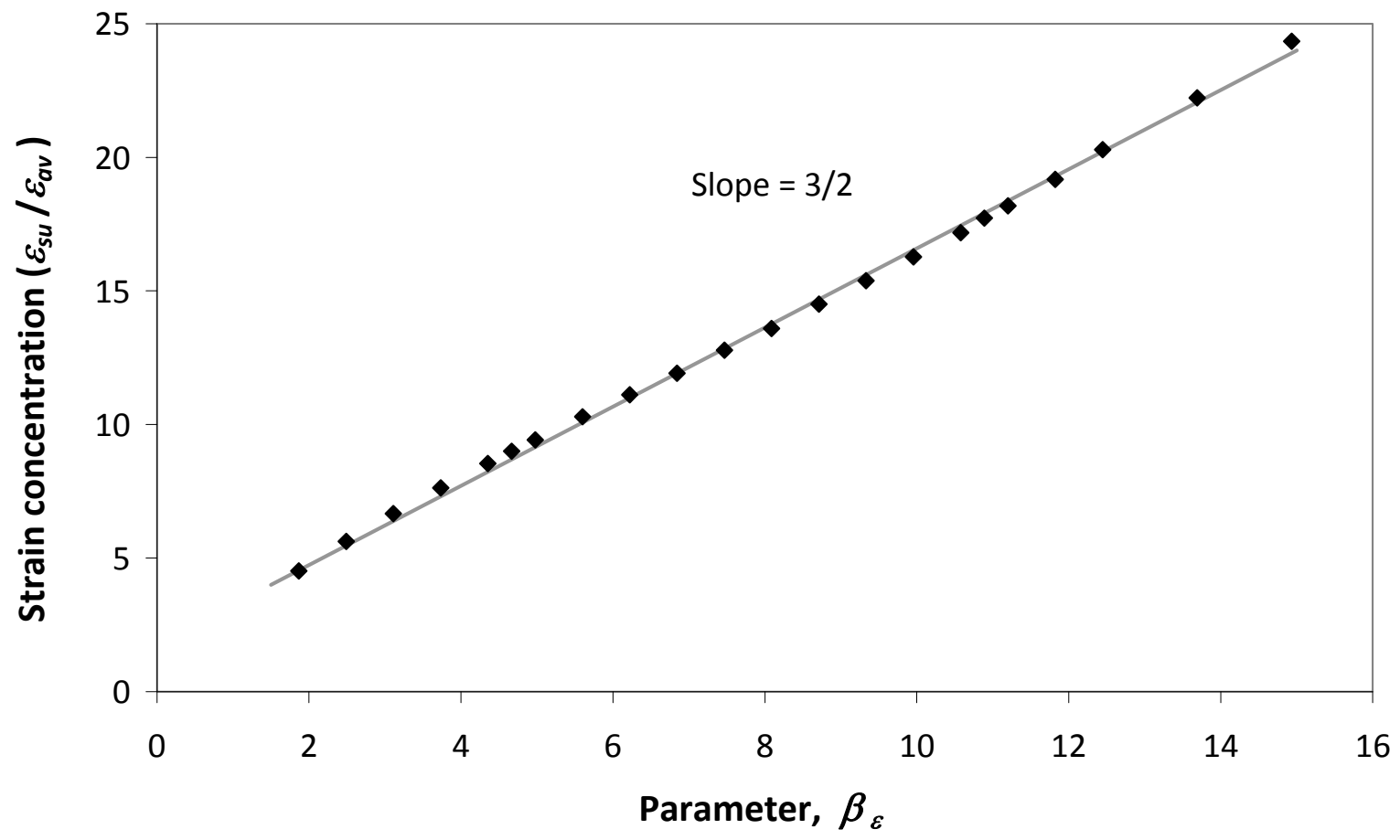

Figure $20 \quad$ Variation of strain concentration in the steel depending on various parameters 


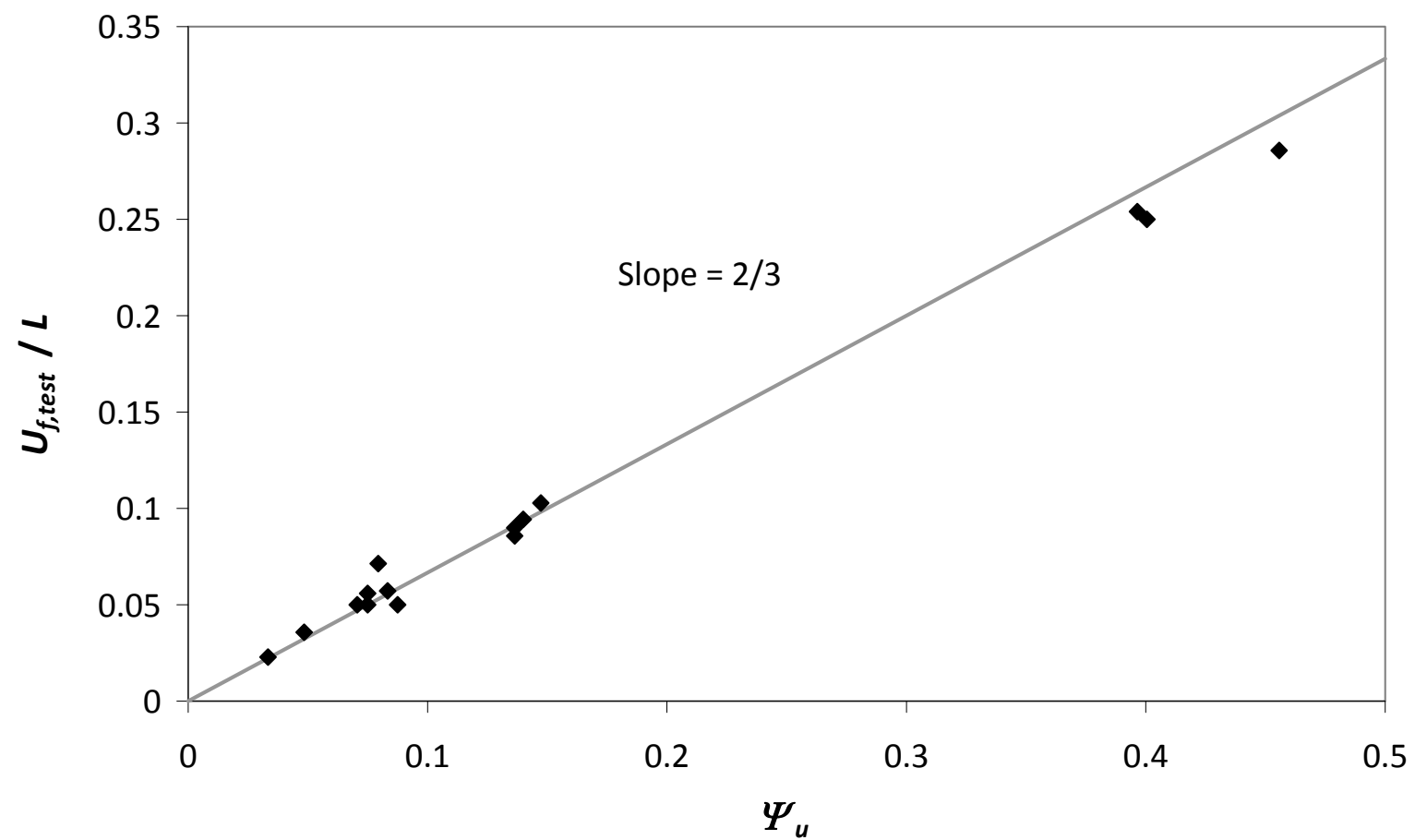

Figure 21 Experimental failure displacements relative to $\Psi_{u}$ 